Article

\title{
Bioactive Dietary VDR Ligands Regulate Genes Encoding Biomarkers of Skin Repair That Are Associated with Risk for Psoriasis
}

\author{
Amitis Karrys ${ }^{1,2,+}{ }^{,}$Islam Rady ${ }^{3,4,+}{ }^{+}$, Roxane-Cherille N. Chamcheu ${ }^{3}$, Marya S. Sabir ${ }^{5}$, \\ Sanchita Mallick ${ }^{5}$, Jean Christopher Chamcheu ${ }^{3,6, *(1)}$, Peter W. Jurutka ${ }^{2,5}$ (D), \\ Mark R. Haussler ${ }^{2}$ and G. Kerr Whitfield ${ }^{2}$ \\ 1 School of Life Sciences, Arizona State University, Tempe, AZ 85281, USA; tkarrys12@gmail.com \\ 2 Department of Basic Medical Sciences, University of Arizona College of Medicine-Phoenix, \\ Phoenix, AZ 85004, USA; peter.jurutka@asu.edu (P.W.J.); haussler@email.arizona.edu (M.R.H.); \\ gkw@email.arizona.edu (G.K.W.) \\ 3 Department of Dermatology, School of Medicine and Public Health, University of Wisconsin, \\ Madison, WI 53706, USA; irady@dermatology.wisc.edu (I.R.); roxanechamcheu@gmail.com (R.-C.N.C.) \\ 4 Department of Zoology, Faculty of Science, Al-Azhar University, P.O. Box 11884 Nazr City, Cairo, Egypt \\ 5 School of Mathematical and Natural Sciences, Arizona State University, Phoenix, AZ 85306, USA; \\ msabir@asu.edu (M.S.S.); smallic5@asu.edu (S.M.) \\ 6 Department of Basic Pharmaceutical Sciences, School of Pharmacy, College of Health \& Pharmaceutical \\ Sciences, University of Louisiana at Monroe, 1800 Bienville Drive, Bienville 362, Monroe, LA 71201, USA \\ * Correspondence: chamcheu@ulm.edu; Tel.: +1-318-342-6820 \\ + These authors contributed equally to this work.
}

Received: 20 November 2017; Accepted: 30 January 2018; Published: 4 February 2018

\begin{abstract}
Treatment with 1,25-dihydroxyvitamin $\mathrm{D}_{3}$ (1,25D) improves psoriasis symptoms, possibly by inducing the expression of late cornified envelope $(L C E) 3$ genes involved in skin repair. In psoriasis patients, the majority of whom harbor genomic deletion of $L C E 3 B$ and $L C E 3 C$ ( $\left.L C E 3 C_{-} L C E 3 B-d e l\right)$, we propose that certain dietary analogues of $1,25 \mathrm{D}$ activate the expression of residual $L C E 3 A / L C E 3 D / L C E 3 E$ genes to compensate for the loss of $L C E 3 B / L C E 3 C$ in the deletant genotype. Herein, human keratinocytes (HEKn) homozygous for LCE3C_LCE3B-del were treated with docosahexaenoic acid (DHA) and curcumin, two low-affinity, nutrient ligands for the vitamin D receptor (VDR). DHA and curcumin induce the expression of LCE3A/LCE3D/LCE3E mRNAs at concentrations corresponding to their affinity for VDR. Moreover, immunohistochemical quantitation revealed that the treatment of keratinocytes with DHA or curcumin stimulates LCE3 protein expression, while simultaneously opposing the tumor necrosis factor-alpha (TNF $\alpha$ )-signaled phosphorylation of mitogen activated protein (MAP) kinases, p38 and Jun amino-terminal kinase (JNK), thereby overcoming inflammation biomarkers elicited by TNF $\alpha$ challenge. Finally, DHA and curcumin modulate two transcription factors relevant to psoriatic inflammation, the activator protein-1 factor Jun B and the nuclear receptor NR4A2/NURR1, that is implicated as a mediator of VDR ligand-triggered gene control. These findings provide insights into the mechanism(s) whereby dietary VDR ligands alter inflammatory and barrier functions relevant to skin repair, and may provide a molecular basis for improved treatments for mild/moderate psoriasis.
\end{abstract}

Keywords: vitamin D receptor; late cornified envelope genes; docosahexaenoic acid; curcumin; epidermis; keratinocytes; psoriasis treatment; nutraceuticals; differentiation; activator protein-1 


\section{Introduction}

Psoriasis is a skin disease of largely unknown etiology with an estimated prevalence of over three percent in the United States [1]. Prominent features include overproliferation and incomplete differentiation of epidermal keratinocytes, as well as epidermal inflammation. Chemical analogs of 1,25 dihydroxyvitamin $\mathrm{D}_{3}(1,25 \mathrm{D})$, the hormonal metabolite of vitamin $\mathrm{D}$, are routinely used as topical agents to treat mild/moderate psoriasis. The success of 1,25D-based agents is presumably related to the reported role of vitamin $\mathrm{D}$ in skin biology, in particular its role in regulating keratinocyte proliferation and differentiation, but also its known ability to regulate components of the immune system in skin (reviewed in [2]). In support of the role of vitamin D (or lack thereof) in psoriasis pathogenesis, several studies have associated low vitamin D status with psoriasis (e.g., [3,4]). However, $1,25 \mathrm{D}$ analog therapy, even when combined with an anti-inflammatory drug (e.g., betamethasone), is not effective in approximately $40 \%$ of patients with mild to moderate psoriasis [5]. Severe cases of psoriasis can be treated effectively with injectable anti-inflammatory agents such as etanercept, adalimumab, infliximab, or secukinumab [6]; however, these agents are not approved for patients with mild/moderate cases [7]. Thus, developing improved topical agents for mild/moderate psoriasis remains an important goal.

The currently accepted paradigm of $1,25 \mathrm{D}$ action is that $1,25 \mathrm{D}$, or an analog thereof, binds with high affinity to the nuclear vitamin $D$ receptor (VDR), which then forms a heterodimer with a retinoid $X$ receptor (RXR) isoform on vitamin D-responsive elements (VDREs) in chromosomal DNA, modulating the expression of nearby target genes [8]. Although 1,25D and its analogs are known to improve psoriasis symptoms in many patients, presumably by serving as VDR ligands, the key epidermal genes that are regulated to ameliorate psoriasis are poorly characterized. One approach to enhancing topical therapies for psoriasis is therefore to identify key genes affected by treatment as well as VDR analogs or other ligands that may optimize these effects. Our approach has been to examine those genes for which genetic variations have been shown to confer risk for psoriasis as potential targets for VDR-mediated regulation.

Psoriasis susceptibility loci (PSORS) include the PSORS4 locus, which is contained within the epidermal differentiation complex (EDC), a large assemblage of over 60 genes expressed during the process of epithelial differentiation (Figure 1). Five closely related late cornified envelope genes (LCE3A-E) exist in a cluster within the EDC and have been reported to play a role in skin repair [9]. The PSORS4 risk allele is a deletion of two of these genes, LCE3C_LCE3B-del, leading to the hypothesis that the loss of two (of five) LCE3 genes might reduce the ability of psoriatic lesions to heal [9]. This deletion is very common and studies have indicated that the frequency of LCE3C_LCE3B-del is over $50 \%$ in many human populations, and is significantly overrepresented in patients with psoriasis, where its frequency increases to $65-75 \%$ of the patient population [10].

The endocrine VDR ligand (1,25D), as well as novel VDR ligands delphinidin and cyanidin, have previously been shown to upregulate $L C E 3$ gene expression to some extent $[11,12]$. Further, a VDRE has been identified adjacent to the LCE3A gene [11] and is not affected by the LCE3C_LCE3B deletion (Figure 1). We have proposed that activation by liganded VDR from this VDRE could coordinately upregulate the expression of the $L C E 3 A / L C E 3 D / L C E 3 E$ genes to compensate for the $L C E 3 C \_L C E 3 B$ deletion under the assumption that the highly homologous $L C E 3$ genes have overlapping functions [13]. We have additionally suggested that delphindin and cyanidin represent candidate lead compounds that could be developed into agents to treat mild to moderate psoriasis in a similar manner to how $1,25 \mathrm{D}$ was utilized as a lead compound to create therapeutically effective analogs such as calcipotriol [14].

For the current study, we analyzed the ability of two additional bioactive lipids of nutritional origin, namely docosahexaenoic acid (DHA) and curcumin, to upregulate LCE3 mRNAs as well as proteins. These two compounds were chosen not only for their demonstrated affinity for the vitamin D receptor [15], but also for their reported beneficial effects in skin. Curcumin has been used since ancient times to treat skin inflammation and other ailments, and its anti-inflammatory actions have been studied in the context of various skin conditions, including pruritus, facial photoaging, 
radiodermatitis, and diabetic microangiopathy (reviewed in [16]). DHA and other omega-3 fatty acids have also been studied for their anti-inflammatory effects, mediated via a variety of mechanisms (reviewed in [17]), including serving as the precursor for the anti-inflammatory molecule resolvin D1 that was recently shown to improve inflammatory symptoms in a mouse imiquimod-induced model of psoriasis [18]. Both DHA [19,20] and curcumin [21,22] have been examined as treatments for psoriasis, but corresponding studies enrolled only a relatively small number of patients and the molecular mechanism(s) accounting for the positive effects observed in a subset of patients were not investigated.

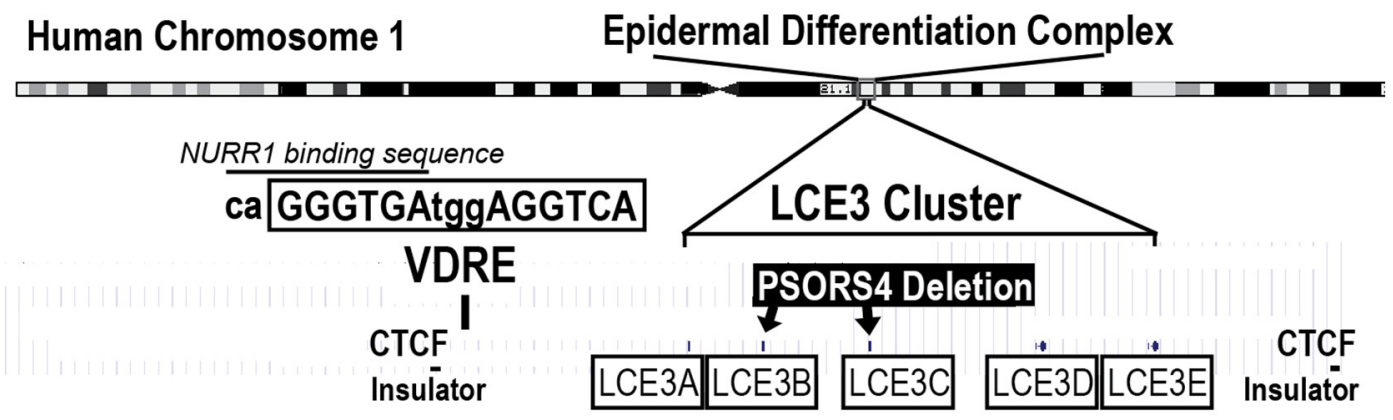

Figure 1. Location of the LCE3 gene cluster (exact location of each gene indicated by a tiny bars above the boxed LCE3 designation) and the common PSORS4 gene deletion within the epidermal differentiation complex on human chromosome 1 that also contains other skin genes such as filaggrin, loricrin, involucrin, and S100A (not shown). The PSORS4 deletion eliminates two LCE3 genes (LCE3C_LCE3B-del), but leaves $L C E 3 A / L C E 3 D / L C E 3 E$ intact. A putative vitamin D-responsive element (VDRE) is located adjacent to the LCE3A gene, but within the boundaries established on either side of the LCE3 gene cluster by sites for the CCCTC-binding factor (CTCF) that may serve to insulate this gene cluster from other nearby genes. This VDRE has been shown to confer responsiveness to both $1,25 \mathrm{D}$ and delphinidin in transfection experiments using a heterologous reporter gene construct [11]. Shown above the VDRE sequence is the location of an overlapping recognition sequence for the nuclear receptor subfamily 4 group A member 2 (NR4A2), also known as NURR1 (see text for explanation).

We also examined the ability of $1,25 \mathrm{D}$, curcumin, and DHA to upregulate the expression of two other disease biomarkers, the activator protein-1 factor Jun B and the nuclear receptor NR4A2, to illuminate additional pathways by which 1,25D, curcumin, and/or DHA might improve psoriasis symptoms. Jun B was selected since the Jun B gene is localized in psoriasis susceptibility locus 6 (PSORS6). Additionally, an inducible epidermal knockout of Jun B in adult mice was reported to yield a phenotype possessing the histological and molecular hallmarks of psoriasis [23]. Further, Jun $B$ expression, similar to LCE3 gene expression, is associated with skin repair [24]. NR4A2, also known as NURR1, nuclear receptor of T cells (NOT), or transcriptionally inducible nuclear receptor (TINUR), was selected for study because a putative VDRE located near the LCE3 gene cluster overlaps with a consensus NR4A2 binding site (Figure 1, caGGGTGA). An additional reason why NR4A2 was of interest is our previously published hypothesis that part of the actions of liganded VDR might be mediated via the upregulation of NR4A2 [25]. Based on the current study, we conclude that both Jun B and NR4A2 may play a role in the action of 1,25D and DHA, and to some extent of curcumin, on skin, but higher doses of ligands are required to demonstrate a statistically significant effect on mRNA levels.

Finally, several literature reports have implied that the effects of DHA in the skin are mediated, not by VDR as we have hypothesized, but rather via peroxisome proliferator-activated receptor (PPAR) isoforms, with PPAR $\delta$ being the dominant isoform in human skin [26]. To assess whether PPAR $\delta$ is a major regulator of LCE genes, we probed GW501516, a selective ligand for PPAR $\delta$, for its ability to upregulate $L C E 3$ genes in keratinocytes. 


\section{Materials and Methods}

\subsection{Source of Ligands and Reagents}

Crystalline 1,25D was obtained from Roche Diagnostics (Indianapolis, IN, USA). Docosahexaenoic acid was purchased from Sigma Aldrich Corporation (St. Louis, MO, USA). GW510516 was secured from Santa Cruz Biotechnology (Dallas, TX, USA). GW501516 and 1,25D were dissolved in ethanol at 1000 times the concentrations needed for cell culture experiments $(1000 \times)$ and stored at $-20{ }^{\circ} \mathrm{C}$. Curcumin was obtained from Cayman Chemical Co. (Ann Arbor, MI, USA), dissolved in dimethyl sulfoxide (DMSO) at $1000 \times$, and stored at $-20^{\circ} \mathrm{C}$. Figure $2 \mathrm{~A}$ depicts the structures of these ligands. An antibody against NR4A2/NURR1 (LS-C99204) was purchased from LifeSpan BioSciences, Inc. (LSBio, Seattle, WA, USA). Antibodies to LCE3B-E (clone C-14, sc-138974), Jun B (clone N-17X, sc-46X), p-JNK (clone G-7, sc-6254), p-p38 (clone D-8, sc-7973), and filaggrin (clone AKH1, sc-66192) were purchased from Santa Cruz Biotechnology (Santa Cruz, CA, USA). Additional antibodies to LCE3B-E proteins were a kind gift from M. Narita in the laboratory of J. Shalkwijk [27]. Alexa Fluor 488-conjugated goat anti-rabbit IgG and Texas Red-conjugated goat anti-mouse IgG secondary antibodies were purchased from Invitrogen Molecular Probes (Eugene, OR, USA). Horseradish peroxidase (HRP) conjugated to anti-mouse IgG and anti-rabbit IgG secondary antibodies were purchased from Cell Signaling Technology (Danvers, MA, USA). The Pierce BCA Protein Assay Kit was from Thermo Scientific (Waltham, MA, USA), and Novex precast Tris-Glycine gels were purchased from Invitrogen (Carlsbad, CA, USA) or Bio-Rad Laboratories (Hercules, CA, USA). Recombinant human Tumor Necrosis Factor-alpha (rhTNF $\alpha$ ) was purchased from R \& D Systems (Minneapolis, MN, USA). ProLong ${ }^{\circledR}$ Gold Anti-fade Reagent containing 4',6-diamidino-2-phenylindole (DAPI) for nuclear staining was obtained from Invitrogen (Carlsbad, CA, USA) and Life Technologies (Grand Island, NY, USA).

A

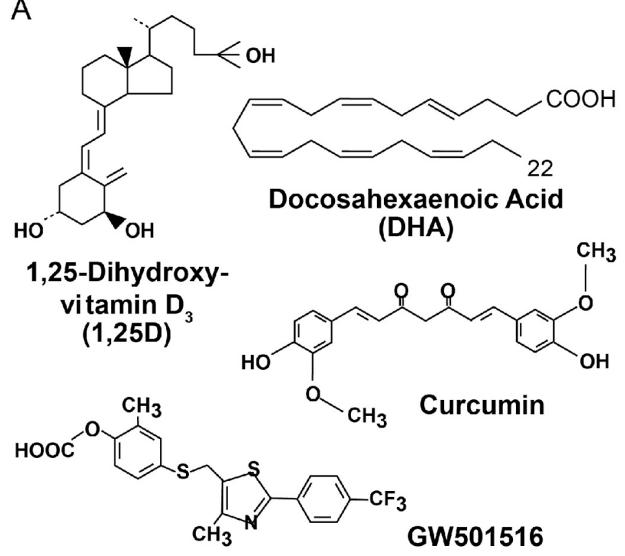

B

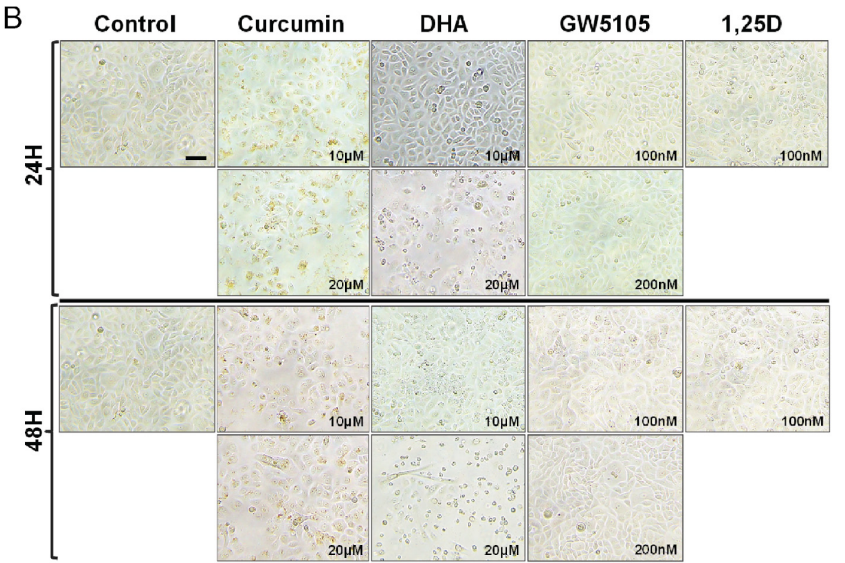

Figure 2. (A) Ligands used in the current study. 1,25D is the natural high affinity ligand for vitamin D receptor (VDR). Curcumin and docosahexaenoic acid (DHA) are natural, low-affinity ligands for VDR, and GW501516 is a specific synthetic ligand for peroxisome proliferator-activated receptor (PPAR) $\delta$, with the latter nuclear receptor also having a reported affinity for DHA. (B) Morphology of normal human epidermal keratinocytes (NHEKs) treated without ligand (control) or with various ligands at the indicated concentrations and time of incubation. Magnification $=300 \times$.

\subsection{Cell Culture and Treatment}

Human primary neonatal keratinocytes (HEKn) from single donors were purchased from Invitrogen Corp. (Carlsbad, CA, USA) and cultured in low calcium serum-free EpiLife medium supplemented with the Human Keratinocytes Growth Supplement Kit (HKGS Kit; Cat\# S-001-K, Thermo Fisher Scientific, Rockford, IL, USA) along with gentamicin and amphotericin from GIBCO (Carlsbad, CA, USA). Cells were re-fed every 2-4 days and split as necessary. Cells were plated at 
550,000 cells per $60-\mathrm{mm}$ dish and treated with $1000 \times$ stocks of calcium chloride (dissolved in water) and/or the ligands of interest (Figure 2A). Rat osteosarcoma cells (UMR-106) were obtained from the American Type Culture Collection (Manassas, VA, USA) and maintained in Dulbecco's Modified Eagles Medium (Hyclone, GE Healthcare, Logan, UT, USA) supplemented with gentamicin/amphotericin in a humidified atmosphere at $37^{\circ} \mathrm{C}$ and $5 \%$ carbon dioxide. For immunofluorescence and Western blot analyses, cells were treated with different concentrations of agents at different time points (24-48 h) prior to harvest and analysis. In some experiments, cells were first pre-incubated or pre-treated for $48 \mathrm{~h}$ with respective ligands/agents and then treated with or without TNF $\alpha(15 \mathrm{ng} / \mathrm{mL})$ for $30 \mathrm{~min}$ prior to harvest.

\subsection{Morphology, Immunocytochemistry, and Immunofluorescence Analysis}

Keratinocytes were seeded in four-chamber tissue culture glass slides and pre-treated with concentrations of each ligand as follows: curcumin $(10-20 \mu \mathrm{M}), 1,25 \mathrm{D}(0.1 \mu \mathrm{M})$, DHA $(10-20 \mu \mathrm{M})$, and GW501516 (100-200 nM), for 24-48 h and processed as earlier described [28]. Briefly, after treatment with (or without) VDR ligands for $48 \mathrm{~h}$, the cells were stimulated for $30 \mathrm{~min}$ before harvest with or without $15 \mathrm{ng} / \mathrm{mL}$ TNF $\alpha$ prior to being washed twice with $1 \times$ phosphate-buffered saline (PBS) $\left(\mathrm{Ca}^{2+} / \mathrm{Mg}^{2+}\right.$-free). Subsequently, cells were fixed in $2 \%$ paraformaldehyde in a 1:1 mix of cold acetone/methanol in PBS for $20 \mathrm{~min}$ at room temperature, followed by $15 \mathrm{~min}$ at $4{ }^{\circ} \mathrm{C}$, followed by three washes in $1 \times$ PBS. Cells were then permeabilized for $5 \mathrm{~min}$ at room temperature with Triton stabilization buffer (0.5\% Triton X-100, $100 \mathrm{mM}$ piperazine- $\mathrm{N}, \mathrm{N}^{\prime}$-bis(2-ethanesulfonic acid (PIPES) buffer ( $\mathrm{K}^{+}$-free), 4\% PEG, and $1 \mathrm{mM}$ ethyleneglycol-bis(aminoethylether)-tetraacetic acid (EGTA)) and washed three times in $1 \times$ PBS. Nonspecific epitopes were blocked with blocking solution (10\% normal goat serum, $2.5 \%$ bovine serum albumin) in PBS for $20 \mathrm{~min}$. Samples were blotted and subsequently incubated overnight at $4{ }^{\circ} \mathrm{C}$ with one of the following monoclonal or polyclonal primary antibodies diluted in blocking buffer: NR4A2/NURR1 (1:100 dilution), LCE3B-E (cross-reacts with four of the five LCE3 protein isoforms [27]) (1:100 dilution), Jun B (1:100 dilution), p-JNK (1:40 dilution), p-p38 (1:100 dilution), or filaggrin (1:50 dilution). Hereafter, the cells were washed three times and incubated with goat anti-rabbit IgG Alexa Fluor 488 or goat anti-mouse IgG-Texas Red secondary antibodies conjugated to HRP, all at 1:600 dilution in blocking buffer, for $45 \mathrm{~min}$ at $37^{\circ} \mathrm{C}$. Slides were washed twice in PBS for 10 min each followed by washing once in double-distilled water, and the cover slips were mounted on glass slides using ProLong ${ }^{\circledR}$ Gold Anti-fade Reagent containing DAPI from Thermo Fisher Scientific (Cat\# P36941, Rockford, IL, USA) for nuclear counter-staining. The mounted slides were allowed to cure overnight in the dark at room temperature. Automated images were acquired using the Nuance Imaging system with a camera equipped on a light microscope as described below.

\subsection{Nuance Multispectral Imaging System FX-Software}

Automated immunofluorescence images were acquired using an Olympus BX43 light microscope (Olympus America Inc., Center Valley, PA, USA) equipped with a CRI camera on a Nuance ${ }^{\mathrm{TM}}$ Imaging FX system version 3.0.2 (Perkin Elmer, Inc., Waltham, MA, USA) using $20 \times / 0.5$ or $40 \times / 0.75$ objectives connected to a computer and an X-Cite ${ }^{\circledR}$ Series 120 Q Sport light source. Data acquisition and image analysis using Nuance software technology plate-form were conducted as previously described $[29,30]$. Briefly, a spectral library was created using image cubes to define distinctive spectral curves for each fluorophore, and counterstained to adjust for background effects and to accurately quantify the positive staining of biomarkers using InForm version 1.4.0 software (Perkin Elmer Inc., Waltham, MA, USA), which allows for an objective analysis of biomarkers with increased accuracy. Isotype controls were used for immunostaining (proportion of green/red pixels for antigen staining) with values averaged from at least five fields for each slide sample. 


\subsection{PSORS4 Genotyping of HEKn Cell Lots}

Genomic DNA was isolated from cells using a DNAeasy kit (Qiagen Corp., Valencia, CA, USA) according to the manufacturer's protocol. A triple primer set was utilized to genotype cells: LCE3CF 5'-TCACCCTGGAACTAGACCTCA-3'; LCE3CR 5'-CTCCAACCACTTGTTCTTCTCA-3'; LCE3CR2D $5^{\prime}$-CATCCCAGGGATGCTGCATG-3' [31]. PCR reactions contained approximately $130 \mathrm{ng} / \mu \mathrm{L}$ of HEKn genomic DNA from a single lot of cells, $0.5 \mu \mathrm{L}$ of an $18 \mu \mathrm{M}$ stock of the above three primers $(0.9 \mu \mathrm{M}$ final concentration of each primer), and $5 \mu \mathrm{L}$ of Fast Start Universal SYBR Green Master Mix from Roche Applied Science (Indianapolis, IN, USA) in a total volume of $10 \mu \mathrm{L}$. An Applied Biosystems 2400 machine was programmed for 35 cycles: $94{ }^{\circ} \mathrm{C}$ for $30 \mathrm{~s}, 60{ }^{\circ} \mathrm{C}$ for $30 \mathrm{~s}$, and $72{ }^{\circ} \mathrm{C}$ for $1 \mathrm{~min}$, followed by a $72{ }^{\circ} \mathrm{C}$ step for $10 \mathrm{~min}$. PCR products were resolved on $3 \%$ agarose gels. A single band at $199 \mathrm{bp}$ indicates that cells harbor a homozygous LCE3C_LCE3B deletion (LCE3C_LCE3B-del), a single band at the position $240 \mathrm{bp}$ indicates a homozygous intact locus, and the presence of both bands signifies a heterozygote.

\subsection{Transient Transfection and Treatment of UMR-106 Cells}

UMR-106 cells were plated at 650,000 cells/well in a 6-well plate. After $24 \mathrm{~h}$ of incubation, the cells were transfected with PolyJet reagent (SignaGen Laboratories, Gaithersburg, MD, USA) according to the manufacturer's protocol. Briefly, each well received $20 \mu \mathrm{L} /$ well PolyJet and $500 \mathrm{ng} /$ well of pSG5-VDR M4, an expression plasmid containing the human VDR cDNA with translation starting at codon 4 (one of the common polymorphic variants of VDR [32]). After $24 \mathrm{~h}$ of incubation, the cells were treated with ethanol vehicle or 1, 10, or $100 \mathrm{nM}$ 1,25D. RNA was harvested after 22-24 h of incubation.

\subsection{Cell Harvesting and Total RNA Preparation}

Cultured cells were harvested by trypsinization using standard techniques and cell pellets were washed with sterile phosphate-buffered saline. RNA isolation was performed using an Aurum Total RNA Mini Kit (Bio-Rad Corp., Hercules, CA, USA) from HEKn cells seeded at 550,000 cells per 60-mm plate and grown to a final confluency of approximately $65-70 \%$. The quantity and purity of prepared RNAs were assessed by UV absorbance at 260 vs. $280 \mathrm{~nm}$. Similar procedures were employed for the UMR-106 cells.

\subsection{Primer Design and Testing}

The UC Santa Cruz Genome Browser [33] was utilized to determine the coding sequence of the genes to be investigated. Unless otherwise referenced, Primer3Plus [34] was used to design primers that spanned an intro-exon junction. For the detection of human LCE3 transcripts, the following primers were used: LCE3A forward primer 5'-CTGAGTCACCACAGATGCCG-3' and reverse primer $5^{\prime}$-CTTGCTGACCACTTCCCCTG-3'; LCE3B forward primer $5^{\prime}$-CTC CTGCTGTGCTCCAAGAC-3' and reverse primer $5^{\prime}$-ATCTTGCTGACCACTGCCTC-3'; LCE3C forward primer $5^{\prime}$-GGTCTG AGGGTTCTGTGCTC-3' and reverse primer $5^{\prime}$-ACACTTGGGT GAGGGACAAC- $3^{\prime}$; LCE3D forward primer $5^{\prime}$-CCCCAAAGAGCCCAGTACAG-3' and reverse primer 5'-CTGTGGTGGTTCAGGAAGCA-3' ; LCE3E forward primer 5'-CCCAAGTGTCCCCCAAAGAA-3 ${ }^{\prime}$ and reverse primer $5^{\prime}$-CTGTGGTGGTTCAGGAAGCA-3'. For the detection of human Jun $B$ and NR4A2 transcripts, the following primers were used: human Jun $B$ forward primer $5^{\prime}$-CGGCAGCTACTTTTCTGGTC-3' and reverse primer 5'-GAAGAGGCGAGCTTGAGAGA-3'; human NR4A2 (NURR1) forward primer 5'-CTACGACGTCAAGCCACCTT-3' and reverse primer 5'-TCATCTCCTCAGACTGGGGG-3'. Human glyceraldehyde 3-phosphate dehydrogenase (GAPDH) mRNA was amplified using forward primer $5^{\prime}$-TGACAACTTTGGTATCGTGGAAGG- $3^{\prime}$ and reverse primer $5^{\prime}$-AGGGATGATGTTCTGGAGAGCC-3'. For the detection of rat transcripts, the following primers were used: rat $N r 4 a 2$ forward primer $5^{\prime}$-CTACGCTTAGCATACAGGTC- $3^{\prime}$ and reverse primer 5'-TTCCTTGAGCCCGTGTCT-3' [35]. Rat GAPDH was amplified using forward primer 
5'-AGGTCGGTGTGAACGGATTTG-3 ${ }^{\prime}$ and reverse primer $5^{\prime}$-CATTCTCAGCCTTGACTGTGC-3' All primer pairs were prepared as $18 \mu \mathrm{M}$ stocks and stored at $-20^{\circ} \mathrm{C}$.

\subsection{Real-Time PCR}

First strand cDNA was synthesized using a Bio-Rad iScript kit from total RNA isolated from HEKn cells. Quantitative real-time PCR was performed with Fast Start Universal SYBR Green Master Mix (Roche Applied Science) in an ABI 7500 Fast thermal cycler, or a BioRad CFX96 thermal cycler for data in Figure 7B only. Each GAPDH PCR well contained $0.5 \mu \mathrm{L}$ of primers, $0.25 \mu \mathrm{L}$ cDNA, and $5 \mu \mathrm{L}$ of SYBR Green reagent mixed in a total volume of $10 \mu \mathrm{L}$. Wells for the detection of other gene products contained $0.5 \mu \mathrm{L}$ of primers, $0.75 \mu \mathrm{L}$ of cDNA, and $5 \mu \mathrm{L}$ of SYBR Green. The temperature profile included 40 cycles with a melting step of $15 \mathrm{~s}$ at $95^{\circ} \mathrm{C}$ and an annealing/elongation step of $1 \mathrm{~min}$ at $60^{\circ} \mathrm{C}$. Real-time PCR data were analyzed via the comparative $C_{t}$ method and normalized to GAPDH. Fold effects for ligand treatments were calculated in relation to the samples treated with ethanol or DMSO vehicle.

\subsection{Protein Extraction and Immunoblotting}

After treatment with different concentrations of ligands at different time points, normal human keratinocyte cells were harvested and whole cell lysates were prepared for Western blot analysis. Briefly, cells were homogenized by sonication in ice-cold $1 \times$ RIPA lysis buffer $(50 \mathrm{mM}$ Tris-HCl, $\mathrm{pH} 7.4$, $150 \mathrm{mM} \mathrm{NaCl}, 1 \mathrm{mM}$ EGTA, $1 \mathrm{mM}$ EDTA, $20 \mathrm{mM} \mathrm{NaF}, 100 \mathrm{mM} \mathrm{Na} 3 \mathrm{VO} 4,0.5 \%$ NP-40, 1\% Triton X-100, $1 \mathrm{mM}$ PMSF) with freshly added protease inhibitor cocktail (Protease Inhibitor Cocktail Set III, Calbiochem, La Jolla, CA, USA). The homogenate was then centrifuged at $14,000 \times g$ for $25 \mathrm{~min}$ at $4{ }^{\circ} \mathrm{C}$, and the supernatant was collected, aliquoted, and stored at $-80{ }^{\circ} \mathrm{C}$. For immunoblotting, $10-20 \mu \mathrm{g}$ of protein was resolved on $8-12 \%$ SDS polyacrylamide (SDS-PAGE) gels and transferred onto nitrocellulose membranes. Blots were incubated in blocking buffer $(5 \%$ non-fat dry milk $/ 1 \%$ Tween 20; in $20 \mathrm{mM}$ Tris-buffered saline (TBS), pH 7.6) for $45 \mathrm{~min}$ at room temperature, followed by incubation with a primary antibody directed against either LCE3B-E, Jun B, or NR4A2/NURR1 in blocking buffer overnight at $4{ }^{\circ} \mathrm{C}$. Following several washes, membranes were incubated with the appropriate $\mathrm{HRP}$-conjugated secondary antibody and detected by enhanced chemiluminescence (ECL) and autoradiography using a Bio-Rad Gel-Doc System (Bio-Rad Laboratories Inc., Hercules, CA, USA). Densitometric measurements of the bands were performed with image analysis software using the Biorad ChemiDoc MP imaging system (Bio-Rad, Hercules, CA, USA). To ensure equal protein loading, membranes were re-probed with antibodies to appropriate house-keeping proteins (GAPDH or vinculin) and processed as above. GAPDH or vinculin data were then used as normalization factors.

\section{Results}

To examine the effects of DHA and curcumin on human neonatal epidermal keratinocytes, we initially monitored the morphology of HEKn cells treated with different concentrations of ligands or vehicle control over time using phase contrast microscopy. As depicted in Figure 2B, we observed that these ligands differentially induced changes in cellular morphology reminiscent of keratinocyte differentiation.

We hypothesized that many of the effects of both DHA and curcumin on keratinocytes are mediated via the vitamin $\mathrm{D}$ receptor (VDR) acting to upregulate the expression of the $L C E 3 A / L C E 3 D / L C E 3 E$ genes. First, we determined if the single-patient sample of HEKn cells harbored the PSORS4 deletion and, if so, whether the deletion was homozygous or heterozygous, using a PCR protocol that incorporated a triple set of primers (see Methods Section 2.5). This reaction yielded a single PCR product at $199 \mathrm{bp}$ (data not shown), indicative of a homozygous LCE3C_LCE3B deletion $\left(L C E 3 C \_L C E 3 B-d e l\right)$. Utilizing a homozygous deletant allowed for a direct test of the hypothesis that DHA and/or curcumin upregulate $L C E 3 A / L C E 3 D / L C E 3 E$ mRNA expression without interfering background from PCR primers annealing to the similar $L C E 3 B$ and/or $L C E 3 C$ mRNAs. 
The first experiment was performed by treating HEKn cells homozygous for LCE3C_LCE3B-del with two concentrations of DHA. The selection of concentrations was based on a previously published competition binding assay [15] which indicated that DHA competes with radioactively labeled $1,25 \mathrm{D}$ for VDR binding with an $\mathrm{IC}_{50}$ of approximately $10 \mu \mathrm{M}$. As shown in Figure 3A, DHA indeed upregulates LCE3 mRNA expression in a dose-dependent manner, with $20 \mu \mathrm{M}$ DHA eliciting 11-fold, 5.5-fold, and 7-fold increases in mRNAs for $L C E 3 A, L C E 3 D$, and LCE3E, respectively. These mRNA effects are superior to the respective 3.6-fold, 4.5-fold, and 4.7-fold increases in mRNAs for LCE3A, $L C E 3 D$, and $L C E 3 E$ reported previously by our group for HEKn cells treated with $100 \mathrm{nM} 1,25 \mathrm{D}$ [11], which serves as a published positive control (employing the hormonal VDR ligand) for the present experiments. To confirm this effect of DHA at the protein level, cells were treated in the presence or absence of single doses of DHA $(10 \mu \mathrm{M})$ with or without activation by recombinant human TNF $\alpha$. Protein expression of $L C E 3$ gene products was monitored by double immunofluorescent microscopy as described in the Methods section; the antibody for LCE3 expression recognizes LCE3B, LCE3C, LCE3D, and LCE3E. As shown in Figure 3B, treatment with $10 \mu \mathrm{M}$ DHA alone for $48 \mathrm{~h}$ strongly induced the expression of LCE3 proteins compared to vehicle control cells (see LCE3B-E column, comparing top two panels), with no discernible effect on the levels of phosphorylated p38 MAP kinase (p-p38). Phospho-p38 was included in the study because it is a pro-inflammatory factor that is activated in psoriasis [36]. Because the pro-inflammatory cytokine TNF $\alpha$ is critically involved in the early phase of psoriasis [37], we next examined the effect of TNF $\alpha$ activation on the response to DHA ligands. As shown in Figure 3B, treatment with TNF $\alpha$ did not discernibly modulate LCE3B-E protein expression, whether in the presence or absence of DHA (LCE3B-E column, compare bottom two panels with top two panels), but strongly induced the phosphorylation of p38 (see p-p38 column, second panel from the bottom). Additionally, the pre-treatment of keratinocytes with DHA for $48 \mathrm{~h}$, prior to activation with TNF $\alpha$ for $30 \mathrm{~min}$, appeared to block the effect of TNF $\alpha$ on p38 phosphorylation (Figure 3B; p-p38 column, bottom panel). A subset of these results was further corroborated by Western blot analyses (see last section of Results below).

A second dietary agent, namely curcumin, a turmeric derivative and bioactive polyphenol, was similarly evaluated in cultured keratinocytes. Because curcumin exhibits a comparable VDR competition profile to DHA (an $\mathrm{IC}_{50}$ of approximately 5-10 $\mu \mathrm{M}$ [15]), and has been reported to be a bona fide VDR ligand [38] with beneficial effects on skin repair [24], we treated HEKn cells with concentrations of curcumin similar to those used for DHA, namely 6.7 and $10 \mu \mathrm{M}$ for mRNA studies and 5, 10, and $20 \mu \mathrm{M}$ for immunocytochemistry. Also, DMSO rather than ethanol was employed as the solvent vehicle for curcumin. The results in Figure $4 \mathrm{~A}$ reveal that curcumin is capable of upregulating $L C E 3 A, L C E 3 D$, and $L C E 3 E$ mRNAs 3- to 4-fold in a dose-dependent manner at concentrations corresponding closely to the concentrations capable of competing with 1,25D for binding to the VDR. This magnitude of induction of LCE3 genes is quite comparable to that of 3.6- to 4.7-fold achieved by $100 \mathrm{nM} 1,25 \mathrm{D}$ as previously published [12]. Immunostaining for protein expression in human keratinocytes confirmed that curcumin treatment alone strongly induced the protein expression of LCE3B-E (Figure 4B; LCE3B-E column, compare top two panels). Analogous to the DHA study shown in Figure 3B, a 30-min treatment with TNF $\alpha$ ( \pm curcumin) was also included (lower two rows of Figure $4 \mathrm{~B}$ ), and there is a suggestion that the combination of curcumin and TNF $\alpha$ yields a higher induction of LCE3B-E protein expression than curcumin alone (Figure 3B, LCE3D-E column, compare second and fourth panels). Finally, the phosphorylation of MAPK p38 in response to the various treatments was also included, with curcumin showing effects similar to DHA, namely an ability to block p38 phosphorylation in response to TNF $\alpha$ (Figure 4B, p-p38 column, compare third and fourth panels). A subset of these results was further corroborated by Western blot analyses (see last section of Results). 

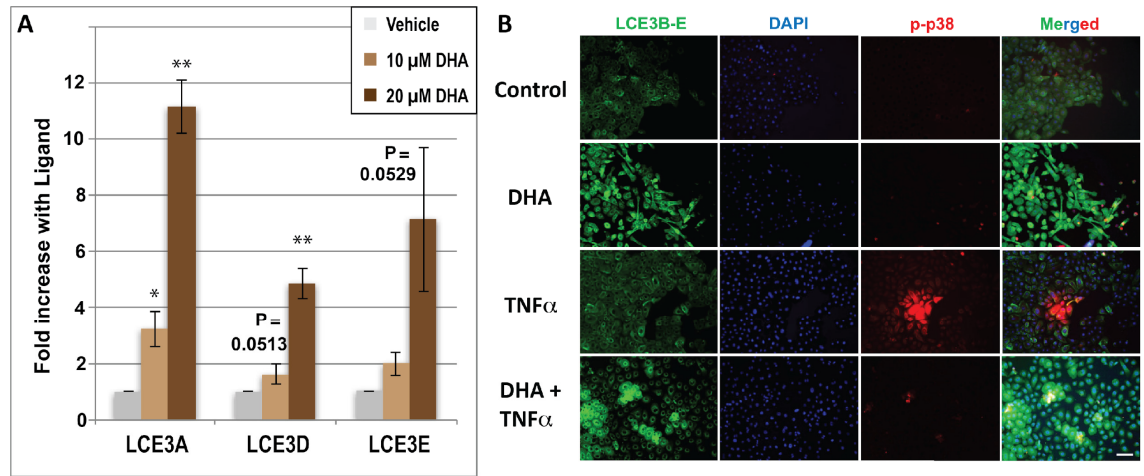

Figure 3. (A) Regulation by docosahexaenoic acid (DHA) of the LCE3A, LCE3D and LCE3E genes spared by the PSORS4 deletion. Human primary neonatal keratinocytes (HEKn) cells homozygous for the deletion were treated with ethanol vehicle (negative control) or DHA (10 or $20 \mu \mathrm{M}$ ), and total RNA was prepared and analyzed for the expression of mRNA using specific primers for each LCE3 isoform. Bar graphs represent the average of three independent experiments \pm STDEV. Asterisks denote results with ligands that are significantly different from ethanol controls as determined by the Student's two-tailed $t$-test: ${ }^{*} p<0.05$; ${ }^{* *} p<0.01$. $p$-Values approaching 0.05 are given above the corresponding bar. (B) Regulation of LCE3 proteins (and p-p38) by DHA and tumor necrosis factor-alpha (TNF $\alpha$ ) as monitored by immunohistochemistry using an antibody that cross-reacts with LCE3B, LCE3C, LCE3D, and LCE3E proteins. Cells were cultured in four chamber tissue culture glass slides and treated for $48 \mathrm{~h}$ with $(10 \mu \mathrm{M})$ or without DHA as indicated. Treatment with TNF $\alpha(15 \mathrm{ng} / \mathrm{mL})$ occurred 30 min prior to fixing and binding of permeabilized cells to the indicated antibodies. Image acquisition is described in Methods and representative images are shown. Images in right-hand column represent a merging of all three signals (LCE3B-3E antibody (green), 4',6-diamidino-2-phenyl (DAPI) (blue), and p-p38 antibody (red)) at a magnification of $\times 200$.
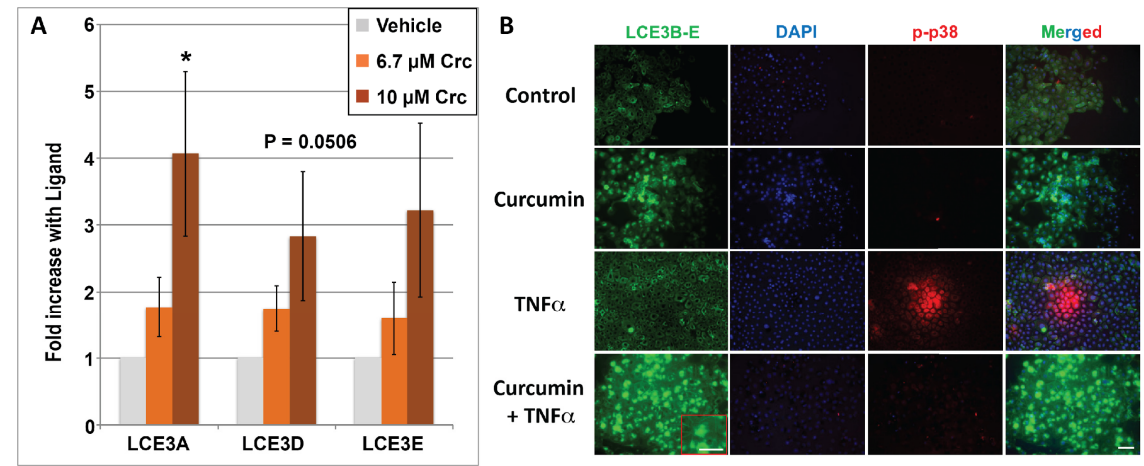

Figure 4. (A) Regulation of $L C E 3 A, L C E 3 D$, and $L C E 3 E$ mRNA by curcumin (Crc). HEKn cells were treated with ETOH vehicle (negative control) or curcumin (at 6.7 or $10 \mu \mathrm{M}$ concentration). Bar graphs show real-time PCR results, which are the average of four independent experiments \pm STDEV. An asterisk denotes ligand-treated averages that are significantly different from ethanol controls as determined by two-tailed Student's $t$-test, ${ }^{*} p<0.05$. One of the four replicates of this experiment was performed with HEKn cells heterozygous for the PSORS4 deletion, which yielded results very similar to the three replicates from homozygous cells. (B) Regulation of LCE3 and p-p38 proteins by curcumin and $\mathrm{TNF} \alpha$ as monitored by immunohistochemistry. Cells were cultured in four chamber tissue culture glass slides and treated for $48 \mathrm{~h}$ with $(15 \mu \mathrm{M})$ or without curcumin as indicated. Treatment with $\mathrm{TNF} \alpha(15 \mathrm{ng} / \mathrm{mL})$ occurred $30 \mathrm{~min}$ prior to fixing and binding of permeabilized cells to the indicated antibodies. Image acquisition is described in Methods and representative images are shown. Images in right-hand column represent a merging of all three signals (LCE3B-3E (green), DAPI (blue), and p-p38 antibody (red)) at a magnification of $\times 200$. Insets in red boxes indicate a higher power magnification $(\times 400)$ of the selected section. 
Although the present data are consistent with the conclusion that DHA is acting as a VDR ligand, literature reports indicate that DHA effects in skin may be mediated by a peroxisome proliferator-activated receptor (PPAR), presumably PPAR $\delta$, which is the predominant isoform expressed in skin [26]. We and others have recently shown that PPAR $\delta$ is overexpressed in human psoriatic as well as in murine psoriasis-like skin lesions [39], and that treatment with delphinidin, another VDR ligand, normalized the expression in a preclinical mouse model of psoriasis [30]. To determine whether PPAR $\delta$ is capable of upregulating LCE3 mRNAs in human keratinocytes, a selective ligand for PPAR $\delta$ (GW501516) was examined at a single $100 \mathrm{nM}$ concentration which, according to published reports, represents a saturating dose for activating PPAR $\delta$ [40]. The results (data not shown) indicated a nonsignificant trend toward a very slight $(<1.5$-fold) upregulation of $L C E 3 A, L C E 3 D$, and LCE3E mRNA expression. Moreover, Western blot data from keratinocytes treated for 24 to $48 \mathrm{~h}$ with two doses of GW501516 (100 and $200 \mathrm{nM}$ ) yielded no significant increase in the expression of LCE3 proteins (see last section of Results). In this same experiment, 10-20 $\mu \mathrm{M}$ DHA or curcumin elicited a statistically significant enhancement in LCE3 protein levels, providing a positive control and indicating that liganded PPAR $\delta$ is not an inducer of LCE3 protein in HEKn cells. Based on these data, we conclude that liganded PPAR $\delta$ plays little or no role in LCE3 gene expression, and this result allows us to distinguish the relative contributions of VDR and PPAR $\delta$ in mediating the actions of DHA with respect to LCE3 maintenance. The conclusion is that VDR alone executes the function of DHA to induce LCE3 gene and protein expression. This does not eliminate potential cross-talk between the signaling of the VDR and PPAR systems in skin, at least with regard to the regulation of genes other than those of the LCE3 class. For example, GW501516 is a strong inducer of NR4A2 protein in HEKn cells, as are 1,25D and curcumin (see last part of Results).

We next assessed whether DHA upregulates Jun B, for which depressed expression or gene deletion has been noted to be associated with psoriasis. Quantitative real-time PCR results (Figure 5A) indicate that DHA significantly upregulates Jun B mRNA expression, but the effect is minimal (2-fold) after $24 \mathrm{~h}$ of treatment, and is not evident until DHA is present at the higher $20 \mu \mathrm{M}$ concentration. Nevertheless, we previously demonstrated Jun B induction by $1,25 \mathrm{D}$ in KERTr human keratinocytes, utilizing microarray technology to quantitate mRNA [8]. In the present report, utilizing immunofluorescence to determine the effects of $48 \mathrm{~h}$ of DHA treatment, we observed an increase in Jun B protein expression (Figure 5B) in both the presence and absence of TNF $\alpha$ treatment. The immunofluorescence experiment also included the monitoring of JNK phosphorylation using a specific phospho-JNK antibody (see p-JNK column in Figure 5B). As expected, JNK is phosphorylated in response to $30 \mathrm{~min}$ of treatment with $\mathrm{TNF} \alpha$, an effect that is largely abolished when $\mathrm{TNF} \alpha$-treated cells are pretreated with DHA (Figure 5B, p-JNK column, compare bottom two panels). The upregulation of Jun B by DHA was confirmed by Western blot analysis (see last section of Results), exhibiting a significant, dose-dependent upregulation of Jun B protein at both 24 and $48 \mathrm{~h}$, approaching the dramatic action of $100 \mathrm{nM} 1,25 \mathrm{D}$ to enhance Jun B protein levels.

The ability of curcumin \pm TNF $\alpha$ to upregulate Jun B expression was also investigated, and Figure 6 illustrates the immunofluorescence results using an anti-Jun B antibody. Treatment with curcumin increased levels of Jun B (Figure 6, Jun B column, compare top two panels), an effect that was confirmed with Western blotting (Figure 8B), which demonstrated a significant and dose-dependent increase in Jun B protein after both 24 and $48 \mathrm{~h}$ of treatment using doses of 5, 10, and $20 \mu \mathrm{M}$. Curcumin also appears to dampen the Jun B-induced phosphorylation of p-JNK by TNF $\alpha$ (Figure 6, p-JNK column, compare bottom two panels). Thus, two low-affinity VDR ligands (DHA and curcumin) evaluated in the present study are able to induce Jun B, as well as to oppose TNF $\alpha$-induced p-JNK phosphorylation.

Finally, we explored the possibility that VDR ligands, including 1,25D, DHA, and curcumin, regulate the expression of the nuclear receptor NURR1, also known as NR4A2, pursuing a notion previously derived conceptually from the recent demonstration that some VDR actions follow a secondary induction mechanism, whereby liganded VDR first induces NURR1, which in turn activates the expression of the gene(s) of interest [25]. Moreover, as noted above, the LCE3 VDRE shown in 
Figure 1 contains within its $5^{\prime}$ half-element a consensus binding sequence for the NR4A2 monomer, caGGGTGA. For these reasons, we examined the level of NURR1 transcripts in DHA-, 1,25D-, and vehicle-treated HEKn cells. The results (Figure 7A) demonstrate that both 1,25D and DHA upregulate NURR1 mRNA in HEKn cells, although there exists no indication of a classic dose-response relationship for DHA, and the results are variable for treatment with 1,25D and $10 \mu \mathrm{M}$ DHA. To definitively demonstrate that NURR1 can be induced in a VDR and ligand dose-dependent fashion, UMR-106 osteoblast-like cells were transfected with human VDR and treated with concentrations of 1,25D from 1 to $100 \mathrm{nM}$. Data for NURR1 mRNA levels compared with vehicle controls, as displayed in Figure 7B, exhibit clear 1,25D dose-dependency for a 3- to 4-fold induction of NURR1 by the hormonal vitamin D. We followed up these mRNA studies by investigating the effect of a single dose of DHA or curcumin treatment using both immunofluorescence as well as Western blotting on the protein expression of NURR1 as well as filaggrin, another biomarker of skin inflammatory disease. Immunofluorescence after $48 \mathrm{~h}$ of treatment with ligands reveals a striking ability of both DHA alone and curcumin alone to upregulate both NURR1 and filaggrin (see NURR1 and filaggrin columns in Figure 7C, comparing second and fourth panels to top control panel). These results were confirmed by Western blotting (Figure 8C). Although the DHA effects pictured in Figure 8C are statistically significant only at the higher $(20 \mu \mathrm{M})$ dose, effects with both DHA and curcumin displayed a dose-response at both time points. Importantly, 1,25D exerts a dramatic positive induction of NURR1 protein in HEKn cells (Figure 8C). Taken together, these results are consistent with the intermediary function of NURR1 as a secondary mediator of at least part of the action of VDR ligands in osteoblasts and skin, with putative occupation of the NURR1 site embedded within the VDRE identified in the LCE gene region being of potential mechanistic significance.
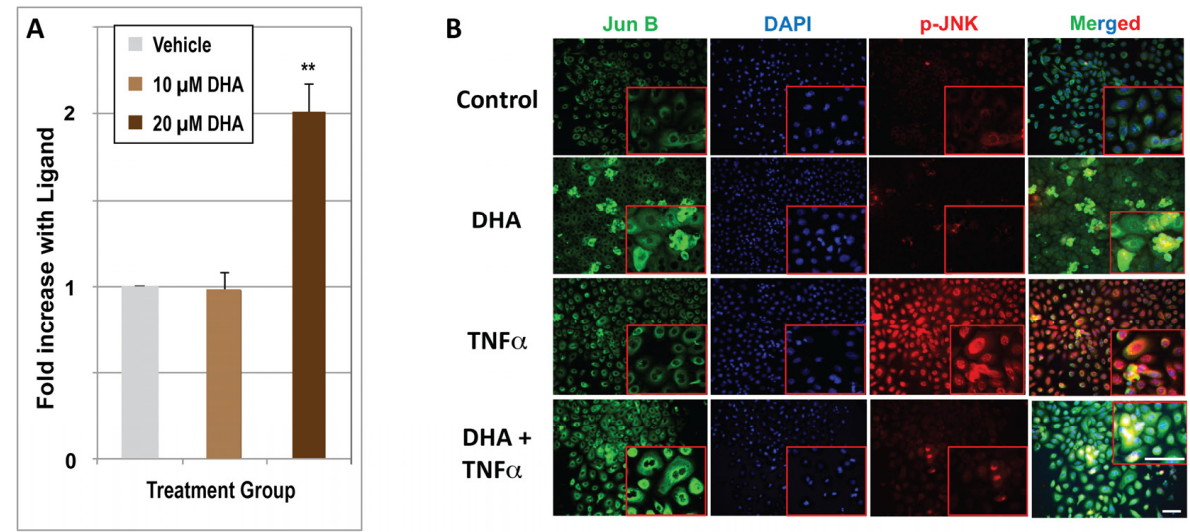

Figure 5. (A) Regulation of Jun B mRNA by DHA. HEKn cells were treated with ethanol vehicle (control), or with either $10 \mu \mathrm{M}$ DHA or $20 \mu \mathrm{M}$ DHA. RNA isolation, synthesis of first strand DNA, and real-time PCR are described in Methods. Results are means from three independent experiments \pm STDEV. The double asterisk $\left.{ }^{* *}\right)$ denotes an average that is statistically significant by Student's $t$-test from the ethanol control, $p<0.01$. (B) Regulation of Jun B and p-JNK proteins by DHA and TNF $\alpha$ as monitored by immunohistochemistry. Cells were cultured in four chamber tissue culture glass slides and treated for $48 \mathrm{~h}$ with $(10 \mu \mathrm{M})$ or without DHA as indicated. Treatment with TNF $\alpha(15 \mathrm{ng} / \mathrm{mL})$ occurred $30 \mathrm{~min}$ prior to fixing and binding of immobilized proteins to the indicated antibodies. Image acquisition is described in Methods and representative images are shown. Images in the right-hand column represent a merging of all three signals (Jun B antibody, DAPI, and p-JNK antibody), measured using Nuance software as described in Methods. (Magnification $\times 200$ ). Insets in red boxes indicate a higher power magnification $(\times 400)$ of the selected section. The yellow color indicates co-localization of both markers. 


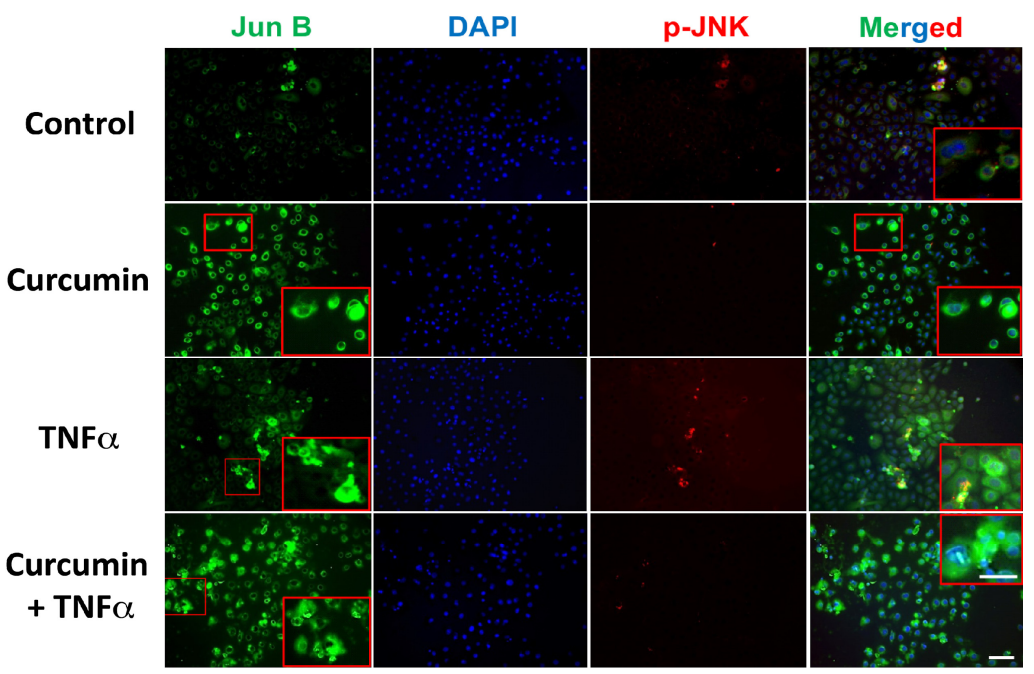

Figure 6. Regulation of Jun B and p-JNK proteins by curcumin and TNF $\alpha$ as monitored by immunohistochemistry. Cells were cultured in four chamber tissue culture glass slides and treated for $48 \mathrm{~h}$ with or without curcumin $(15 \mu \mathrm{M})$ as indicated. Treatment with TNF $\alpha(15 \mathrm{ng} / \mathrm{mL})$ occurred $30 \mathrm{~min}$ prior to fixing in $2 \%$ paraformaldehyde and binding of immobilized proteins to the indicated antibodies. Image acquisition is described in Methods and representative images are shown. Images in right-hand column represent a merging of all three signals (Jun B antibody, DAPI and p-JNK antibody), measured using Nuance software as described in Methods. (Magnification $\times 200$ ). Insets in red boxes indicate a higher power magnification $(\times 400)$ of the selected section.
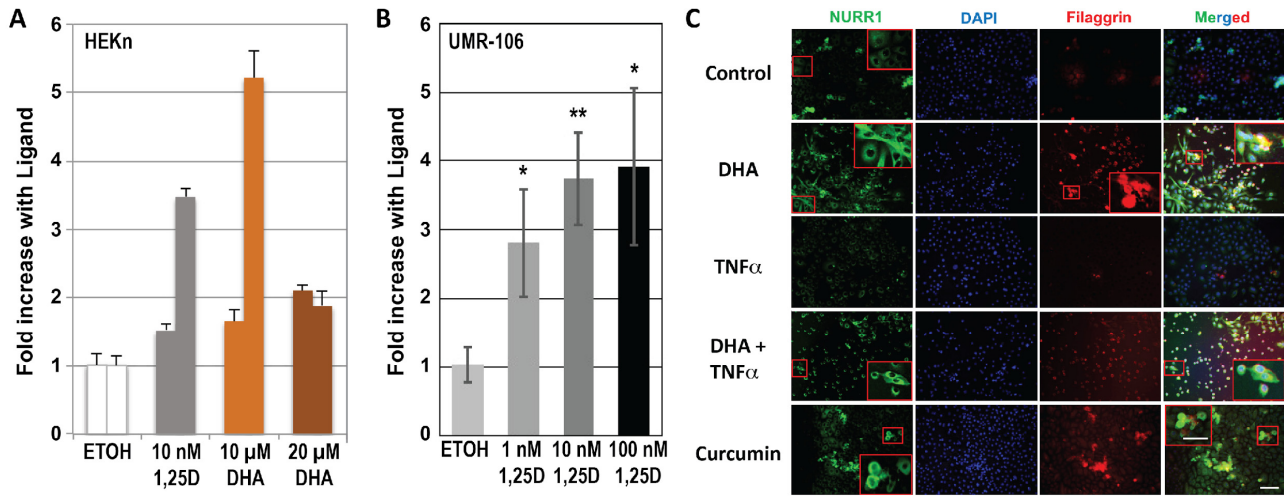

Figure 7. Regulation of NURR1 (NR4A2) mRNA by 1,25D. (A) Response of NURR1 mRNA to 1,25D and DHA in HEKn cells. Cells were plated as described in Methods and dosed with the indicated concentrations of 1,25D or DHA for 22-24 h. Total RNA and first strand cDNA were then prepared, and real-time qPCR was performed using primers to human NURR1 as described in Methods. Error bars represent STDEV of triplicate real-time PCR wells from each of two independent experiments. (B) A similar experiment to (A), but performed using increasing doses of 1,25D in rat UMR-106 cultures. Results are means of three independent experiments \pm STDEV, ${ }^{*} p<0.05,{ }^{* *} p<0.01$ compared to control by Student's $t$-test. (C) Regulation of NURR1 and filaggrin proteins by DHA and TNF $\alpha$ as monitored by immunohistochemistry. Cells were cultured in tissue culture glass slides and treated for $48 \mathrm{~h}$ with $(10 \mu \mathrm{M})$ or without DHA as indicated. Treatment with TNF $\alpha(15 \mathrm{ng} / \mathrm{mL})$ occurred $30 \mathrm{~min}$ prior to fixing in $2 \%$ paraformaldehyde and binding of immobilized proteins to the indicated antibodies. Image acquisition is described in Methods and representative images are shown. Images in right-hand column represent a merging of all three signals (NURR1 antibody, DAPI and filaggrin antibody), measured using Nuance software as described in Methods. (Magnification $\times 200$ ). Insets in red boxes indicate a high power magnification $(\times 400)$ of the highlighted section. 
A

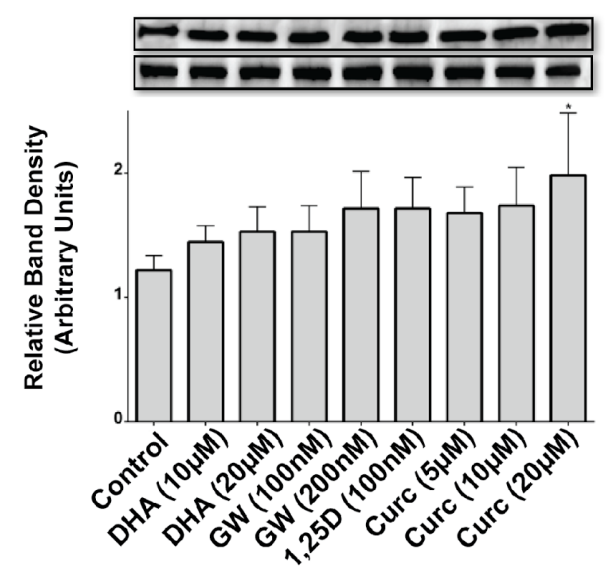

B
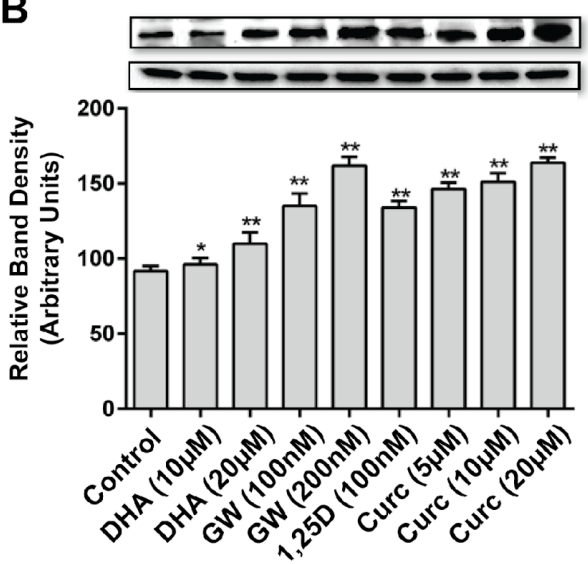

C

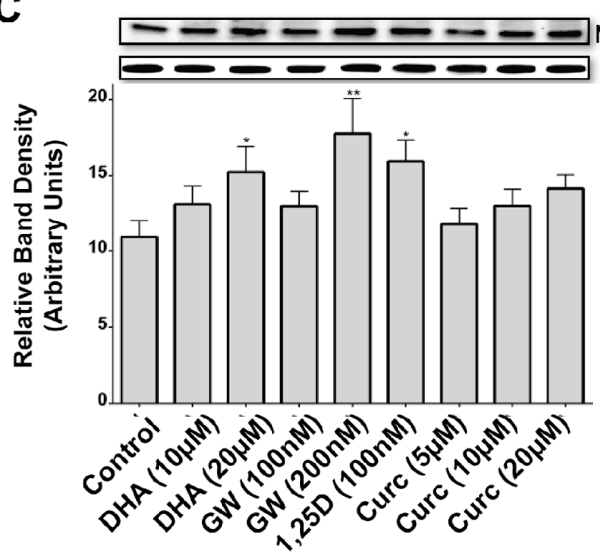

$48 h$
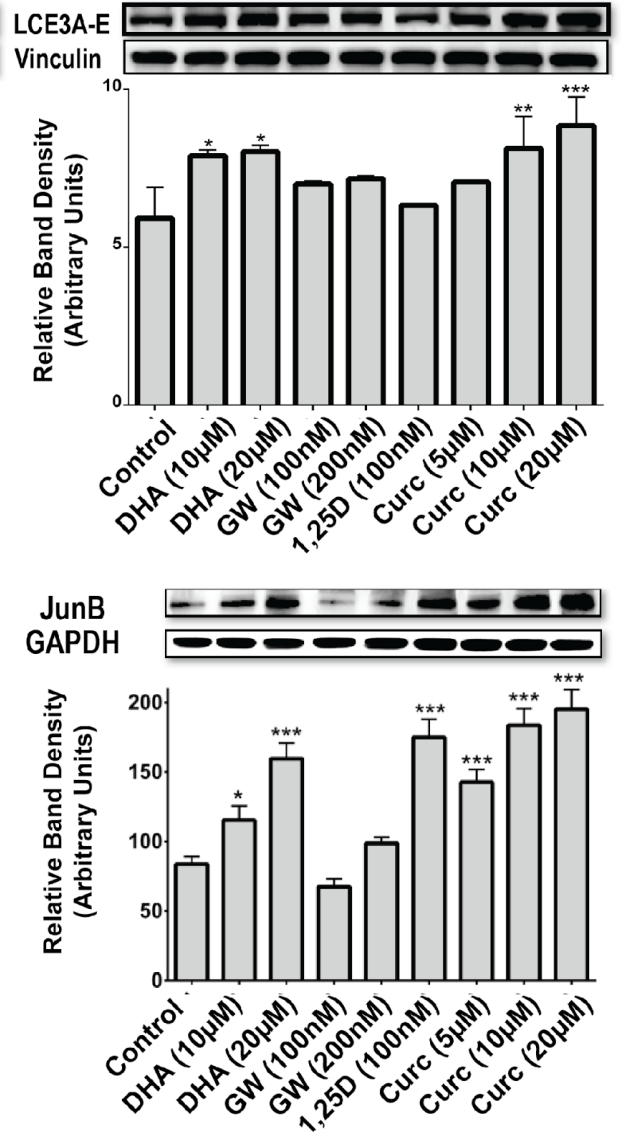

NR4A2 (NURR1) -----
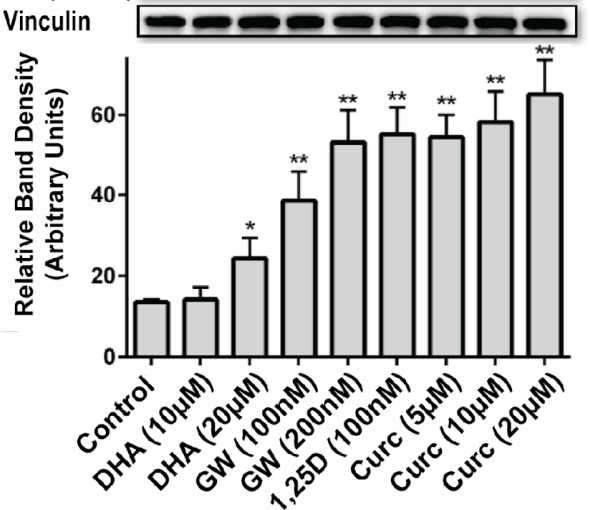

Figure 8. Dose-dependency of protein expression in response to 1,25D, curcumin (Curc) (ligand for the vitamin D receptor), GW501516 (GW; ligand for PPARס), and DHA (ligand for both receptors). (A) Protein expression for LCE3 proteins as monitored by an antibody that recognizes four LCE3 isoforms (LCE3B/LCE3C/LCE3D/LCE3E), using Vinculin expression as an unregulated control to normalize for protein loading. (B) Protein expression of Jun B, using GAPDH as an unregulated control. (C) Protein expression of NR4A2 (NURR1), using Vinculin as an unregulated control. All bars represent an average of at least five fields for each sample (blots were normalized using Chemidoc quantification analysis software as described in Methods) \pm STDEV. ${ }^{*} p<0.5,{ }^{* *} p<0.01,{ }^{* * *} p<0.001$.

\section{Discussion and Conclusions}

Analogs of 1,25D are used routinely for psoriasis treatment, often in combination with an anti-inflammatory steroid [41]. Previous studies from our laboratory have pursued the hypothesis 
that 1,25D and other VDR ligands improve symptoms of psoriasis by upregulating skin repair genes, and in two recent publications by our group, we reported that the VDR ligands 1,25D, delphinidin, and cyanidin upregulate $L C E 3 A / L C E 3 D / L C E 3 E$ gene expression, potentially to compensate for the common genomic deletion of $L C E 3 B$ and $L C E 3 C[11,12]$.

The dietary lipids DHA (an omega-3 fatty acid) and curcumin (a bioactive component of turmeric spice) were selected for investigation as both have been subjects of clinical trials for the treatment of psoriasis (NCT01351805 and NCT00235625). In addition to these clinical trials, dietary studies have concluded that psoriatic patients typically consume diets low in omega-3 fatty acids, including DHA [42], and conversely, that a diet low in calories but high in omega-3 fatty acids appears to confer a better response to immunomodulatory drugs in a cohort of obese patients with plaque-type psoriasis [43]. Another dietary study found that adherence to a Mediterranean diet was inversely related to psoriasis area severity index (PASI) score, and that high consumption of fish (which contain omega-3 fatty acids including DHA) was independently negatively associated with a high PASI score [44]. Although it is difficult to separate the potential effects of DHA from those of other dietary components, these studies, taken together, suggest that consumption of omega-3 fatty acids, including DHA, may represent a useful adjuvant to other psoriasis therapies.

In addition to other modes of action, the current study pursues the notion that DHA and curcumin may act as VDR ligands to regulate genes involved in psoriasis pathology. Both DHA and curcumin have been shown, like other alternative, low-affinity VDR ligands such as delphinidin and cyanidin, to compete with 1,25D for direct, low-affinity binding to VDR [15]. The data shown in Figure 3 indicate that DHA significantly upregulates $L C E 3$ gene expression in cells homozygous for $L C E 3 C \_L C E 3 B$-del. We propose that this induction of $L C E 3$ gene products compensates for the loss of $L C E 3 B$ and $L C E 3 C$ in skin repair, under the assumption that the highly similar $L C E 3$ gene products are functionally redundant [27]. Curcumin was also demonstrated to be capable of upregulating LCE3A, LCE3D, and LCE3E genes (Figure 4). Given that the effective concentrations of DHA and curcumin employed in these experiments coincide with those that competitively bind to VDR, we postulate that these ligands upregulate $L C E 3$ gene expression, at least in part, by binding to, and activating the VDR-RXR heterodimer. Our previous work identified a VDRE adjacent to the LCE3A gene (Figure 1) that is capable of conferring regulation onto a heterologous reporter gene by 1,25D, delphinidin, or cyanidin in transfected CCD-1106 KERTr human keratinocyte cells [11], lending further support to the notion that liganded VDR may induce the expression of these genes in vivo.

Recent reports reveal that the presence of $L C E 3 C_{-} L C E 3 B$-del within the LCE3 gene cluster has a lengthy evolutionary history in the hominid lineage. The deletion appears to have arisen in the common ancestor to modern humans and Denisovans [45,46]. Based on an analysis of genomic DNA from ancient hominins as well as modern humans, including a haplotype analysis of the deletion as well as flanking regions in the LCE3 locus, the authors of these studies conclude that the $32 \mathrm{~kb}$ LCE3C_LCE3B deletion has been maintained under balancing selection in the human lineage. In considering the potential reasons as to why both LCE3 haplotypes are currently found in all tested human populations, including those from Eurasia, Africa, and the Americas [46,47], these authors quoted Bergboer et al. [48], who hypothesized that LCE3C_LCE3B-del, by delaying skin repair, could allow for greater penetration of microbial antigens, which then serve as a natural "vaccine" against future infections (while also posing an increased risk for an autoimmune response). Further, the hypothesis explaining the retention of the intact $L C E 3$ cluster is that the full complement of five $L C E 3$ genes confers a superior ability to support skin repair. Whatever the exact explanation, it appears that an interplay between these two sets of advantages/disadvantages has led to the preservation of both alleles in a state of balance over hundreds of thousands of years.

The extent to which DHA upregulates LCE3 mRNA expression exceeds 10-fold in the case of $L C E 3 A$, which is noticeably greater than the approximate 4 -fold achieved by $10^{-8} \mathrm{M} 1,25 \mathrm{D}$ in prior studies [11,12]. This comparison suggests that, at least for the upregulation of $L C E 3$ gene expression, DHA may be superior to the currently used therapeutic agent 1,25D (or analogs thereof), taking into 
account that higher concentrations of DHA are required [19] to achieve this effect due to the lower affinity of DHA for the receptor. This result positions both DHA and the previously tested cyanidin compound [11] as two dietary, non-toxic nutrients that are each capable of upregulating the expression of LCE3 skin repair genes in a fashion superior to that of $1,25 \mathrm{D}$, the currently used anti-psoriatic agent. Moreover, curcumin is yet another candidate alternative to $1,25 \mathrm{D}$ chemical analogs for psoriasis treatment, as its 3- to 4 -fold action to induce $L C E 3 A$ mRNA (Figures $4 \mathrm{~A}$ and $8 \mathrm{~A}$ ) is equivalent in magnitude to the effect of $100 \mathrm{nM} 1,25 \mathrm{D}$, but curcumin is less prone than 1,25D to induce toxic hypercalcemia and likely is endowed with beneficial influences not intrinsic to 1,25D.

The results presented herein (Figures 3-5) do not rule out the possibility that DHA, curcumin, or other VDR ligands may act on LCE3 gene transcription via additional mechanisms. Indeed, literature reports have suggested that DHA effects in the skin are mediated, not by VDR, but rather via peroxisome proliferator-activated receptor (PPAR) isoforms such as PPAR $\delta$ [26]. Furthermore, the doses of DHA that are capable of activating PPAR $\delta$ are similar to doses necessary for the activation of VDR [49]. By observing that treatment with a saturating concentration of the PPAR $\delta$ ligand GW501516 only modestly (and not statistically significantly) upregulated LCE3A, LCE3D, and LCE3E mRNAs (data not shown), and did not significantly enhance LCE3 protein expression (Figure 8A), we conclude that the effect of DHA on LCE3 gene expression is exerted predominantly via the activation of VDR. Thus, DHA appears to function via a mechanism involving the association of liganded VDR with VDREs in target genes. To prove conclusively that liganded VDR docks on the postulated LCE3 gene region VDRE (Figure 1) will require in vivo ChIP-seq experiments in skin, a technical challenge which is beyond the scope of the current investigation, but is warranted for future studies.

The involvement of TNF $\alpha$ in the pathogenesis of psoriasis is well documented [50] and is the target of biological therapies that have proven effectiveness in severe cases [51]. The involvement of the MAP kinase $\mathrm{p} 38$ in the pathogenesis of psoriasis and its activation by the TNF $\alpha$ pathway are also well established [52]. We therefore investigated whether the VDR ligands DHA and curcumin could impact p38 phosphorylation in response to TNF $\alpha$ treatment of keratinocytes. Our finding that both ligands inhibit TNF $\alpha$-induced p38 phosphorylation (Figures 3B and 4B) suggests that these VDR ligands have anti-psoriatic actions besides the induction of skin repair involving LCE3 gene products. The effects of both ligands on TNF $\alpha$ signaling are similar to those observed in the imiquimod-induced mouse models of psoriasis by curcumin [53], and in other tissues, such as rat endothelial cells, by DHA [54]. In the case of DHA, the involvement of PPAR receptors such as PPAR $\gamma$ in these effects cannot be excluded (see [55]). Similarly, the effect of TNF $\alpha$ on JNK phosphorylation is also relevant to psoriasis [56]. Again, the pretreatment of keratinocytes with either DHA or curcumin inhibited the TNF $\alpha$-induced phosphorylation of JNK (Figures 5B and 6), another indication that the anti-psoriatic mechanisms of these ligands extend to the TNF $\alpha$ pathway, which is successfully targeted by biologic treatments for moderate to severe psoriasis.

As a concluding experiment in this study, we evaluated whether VDR ligands, including DHA, 1,25D, and curcumin, regulate the expression of the nuclear receptor NURR1, also known as NR4A2, based on recent insight that specific VDR actions appear to involve a secondary mechanism whereby liganded VDR upregulates NURR1 expression, which in turn activates the expression the gene(s) of interest [25]. Moreover, increased expression of NURR1 mRNA and protein occurs in involved psoriasis skin compared with uninvolved and normal skin [57], which is consistent with another recent report showing that NURR1 expression is crucial for the development of mature, fully functional Th17 cells [58] that have, in turn, been shown to play an important role in psoriasis pathogenesis via the production of IL-17 and IL-23 cytokines [59]. For these reasons, it was of interest to investigate the potential ability of DHA, curcumin, and 1,25D to control NURR1 expression. The results (Figures 7 and $8 \mathrm{C}$ ) revealed that DHA, curcumin, and 1,25D induce, rather than repress, NURR1 expression, consistent with the hypothesis that NURR1 acts as a secondary mediator of at least part of the function of VDR ligands to induce skin repair genes such as the LCEs. However, because NURR1 is apparently a pro-psoriatic transcription factor in human skin [57], its induction by VDR 
ligands complicates our understanding of the mechanism whereby vitamin $\mathrm{D}$ analogs are effective in suppressing mild to moderate psoriasis symptoms. In other words, by inducing NURR1, VDR ligands could conceivably aggravate inflammation and proliferation as collateral effects to inducing skin repair genes, although one could argue that NURR1 is actually a trigger for normal skin remodeling in place of psoriatic pathology. It is also possible that the relative timing of NURR1 upregulation might be important with respect to its effects on inflammation and/or proliferation versus skin repair, an issue that could be addressed in future studies. In conclusion, identified herein is a secondary induction mechanism whereby VDR ligands increase the expression of NURR1, which in turn may function as the primary inducer of skin repair genes such as the LCE3 ensemble. Again, proof of this concept will require in vivo ChIP-seq experiments in skin, determining whether NURR1 is the transcription factor actually docked on the composite response element for VDR and NURR1 identified in the LCE3 gene region (Figure 1).

Given the lack of understanding of how 1,25D analogs improve symptoms of psoriasis, the effect of these compounds, as well as low-affinity VDR ligands such as DHA, curcumin, cyanidin, delphinidin, and others, could be examined on the expression of genes harbored in different loci. One of many possible examples is secreted mammalian Ly6/urokinase plasminogen activator receptor-related protein (SLURP-2), a gene that is strongly induced in psoriatic skin lesions [60]. Finally, since 14,21-dihydroxy-DHA has been shown to be a dramatic wound healing lipid in murine models [61], it is tempting to speculate that cellular metabolites of DHA, and possibly other low-affinity VDR ligands, could be discovered as high-affinity nuclear receptor ligands. These novel super-bioactive metabolites, if identified, could prove vastly more efficacious than their low-affinity VDR ligand precursors or even than 1,25D itself. In conclusion, the present investigation reveals the ability of nutrient or diet-derived VDR ligands to upregulate specific skin-expressed genes and proteins with relevance for psoriasis, and sets the stage for future studies examining the regulation of psoriasis-related skin-expressed genes by novel metabolites of low-affinity VDR ligands such as DHA and curcumin, potentially leading to drug discovery of new molecular-based treatments for mild/moderate psoriasis. Further studies beyond the scope of the current manuscript are warranted to critically examine these observations and to decipher their detailed molecular mechanisms.

Acknowledgments: This work was supported in part by grants NIH DK033351 to M.R.H., NIH CA140285 to P.W.J., a POHOFI Inc., Pre-College Intern Scholarship Award to R.C.N.C., a American Skin Association (ASA) Carson Research Scholar Award in Psoriasis to J.C.C., a UW-Madison Skin Disease Research Center (SDRC) Pilot and Feasibility Research Award to J.C.C. from NIH/NIAMS grant P30 AR066524, funding from the University of Louisiana at Monroe School of Pharmacy to J.C.C., and a grant from the University of Arizona, Department of Basic Medical Sciences to G.K.W.

Author Contributions: A.K., I.R. and R.C.N.C. performed most of the experimental work, and A.K. wrote the first draft of the manuscript. J.C.C. and G.K.W. designed and supervised the work, and performed most of the data analysis and manuscript editing. M.S.S. and S.M. performed the experiment and data analysis for Figure 7B as well as aided in manuscript editing. P.W.J. and M.R.H. provided laboratory and grant support for the project, as well as key insights into the planning of the project, interpretation of the data, and placing the conclusions into the context of the broader field. All authors read and approved the final submitted version of this manuscript.

Conflicts of Interest: The authors declare no conflict of interest.

\section{References}

1. Rachakonda, T.D.; Schupp, C.W.; Armstrong, A.W. Psoriasis prevalence among adults in the United States. J. Am. Acad. Dermatol. 2014, 70, 512-516. [CrossRef] [PubMed]

2. Barrea, L.; Savanelli, M.C.; Somma, C.D.; Napolitano, M.; Megna, M.; Colao, A.; Savastano, S. Vitamin D and its role in psoriasis: An overview of the dermatologist and nutritionist. Rev. Endocr. Metab. Disord. 2017, 18, 195-205. [CrossRef] [PubMed]

3. Gisondi, P.; Rossini, M.; Di Cesare, A.; Idolazzi, L.; Farina, S.; Beltrami, G.; Peris, K.; Girolomoni, G. Vitamin D status in patients with chronic plaque psoriasis. Br. J. Dermatol. 2012, 166, 505-510. [CrossRef] [PubMed] 
4. Orgaz-Molina, J.; Buendia-Eisman, A.; Arrabal-Polo, M.A.; Ruiz, J.C.; Arias-Santiago, S. Deficiency of serum concentration of 25-hydroxyvitamin D in psoriatic patients: A case-control study. J. Am. Acad. Dermatol. 2012, 67, 931-938. [CrossRef] [PubMed]

5. Devaux, S.; Castela, A.; Archier, E.; Gallini, A.; Joly, P.; Misery, L.; Aractingi, S.; Aubin, F.; Bachelez, H.; Cribier, B.; et al. Topical vitamin D analogues alone or in association with topical steroids for psoriasis: A systematic review. J. Eur. Acad. Dermatol. Venereol. 2012, 26, 52-60. [CrossRef] [PubMed]

6. Kim, I.H.; West, C.E.; Kwatra, S.G.; Feldman, S.R.; O’Neill, J.L. Comparative efficacy of biologics in psoriasis: A review. Am. J. Clin. Dermatol. 2012, 13, 365-374. [CrossRef] [PubMed]

7. Crow, J.M. Therapeutics: Silencing psoriasis. Nature 2012, 492, S58-S59. [CrossRef] [PubMed]

8. Haussler, M.R.; Whitfield, G.K.; Kaneko, I.; Haussler, C.A.; Hsieh, D.; Hsieh, J.C.; Jurutka, P.W. Molecular mechanisms of vitamin D action. Calcif. Tissue Int. 2013, 92, 77-98. [CrossRef] [PubMed]

9. Bergboer, J.G.; Tjabringa, G.S.; Kamsteeg, M.; van Vlijmen-Willems, I.M.; Rodijk-Olthuis, D.; Jansen, P.A.; Thuret, J.Y.; Narita, M.; Ishida-Yamamoto, A.; Zeeuwen, P.L.; et al. Psoriasis risk genes of the late cornified envelope-3 group are distinctly expressed compared with genes of other LCE groups. Am. J. Pathol. 2011, 178, 1470-1477. [CrossRef] [PubMed]

10. Riveira-Munoz, E.; He, S.M.; Escaramis, G.; Stuart, P.E.; Huffmeier, U.; Lee, C.; Kirby, B.; Oka, A.; Giardina, E.; Liao, W.; et al. Meta-analysis confirms the LCE3C_LCE3B deletion as a risk factor for psoriasis in several ethnic groups and finds interaction with HLA-CW6. J. Investig. Dermatol. 2011, 131, 1105-1109. [CrossRef] [PubMed]

11. Austin, H.R.; Hoss, E.; Batie, S.F.; Moffet, E.W.; Jurutka, P.W.; Haussler, M.R.; Whitfield, G.K. Regulation of late cornified envelope genes relevant to psoriasis risk by plant-derived cyanidin. Biochem. Biophys. Res. Commun. 2014, 443, 1275-1279. [CrossRef] [PubMed]

12. Hoss, E.; Austin, H.R.; Batie, S.F.; Jurutka, P.W.; Haussler, M.R.; Whitfield, G.K. Control of late cornified envelope genes relevant to psoriasis risk: Upregulation by 1,25-dihydroxyvitamin D3 and plant-derived delphinidin. Arch. Dermatol. Res. 2013, 305, 867-878. [CrossRef] [PubMed]

13. Jackson, B.; Tilli, C.M.; Hardman, M.J.; Avilion, A.A.; MacLeod, M.C.; Ashcroft, G.S.; Byrne, C. Late cornified envelope family in differentiating epithelia-response to calcium and ultraviolet irradiation. J. Investig. Dermatol. 2005, 124, 1062-1070. [CrossRef] [PubMed]

14. Reichrath, J.; Müller, S.M.; Kerber, A.; Baum, H.P.; Bahmer, F.A. Biologic effects of topical calcipotriol (MC 903) treatment in psoriatic skin. J. Am. Acad. Dermatol. 1997, 36, 19-28. [CrossRef]

15. Haussler, M.R.; Haussler, C.A.; Bartik, L.; Whitfield, G.K.; Hsieh, J.C.; Slater, S.; Jurutka, P.W. Vitamin D receptor: Molecular signaling and actions of nutritional ligands in disease prevention. Nutr. Rev. 2008, 66, S98-S112. [CrossRef] [PubMed]

16. Vaughn, A.R.; Branum, A.; Sivamani, R.K. Effects of turmeric (Curcuma longa) on skin health: A systematic review of the clinical evidence. Phytother. Res. 2016, 30, 1243-1264. [CrossRef] [PubMed]

17. Calder, P.C. Omega-3 fatty acids and inflammatory processes: From molecules to man. Biochem. Soc. Trans. 2017, 45, 1105-1115. [CrossRef] [PubMed]

18. Xu, J.; Duan, X.; Hu, F.; Poorun, D.; Liu, X.; Wang, X.; Zhang, S.; Gan, L.; He, M.; Zhu, K.; et al. Resolvin D1 attenuates imiquimod-induced mice psoriasiform dermatitis through mapks and nf-kappab pathways. J. Dermatol. Sci. 2017. [CrossRef]

19. Mayser, P.; Mrowietz, U.; Arenberger, P.; Bartak, P.; Buchvald, J.; Christophers, E.; Jablonska, S.; Salmhofer, W.; Schill, W.B.; Kramer, H.J.; et al. Omega-3 fatty acid-based lipid infusion in patients with chronic plaque psoriasis: Results of a double-blind, randomized, placebo-controlled, multicenter trial. J. Am. Acad. Dermatol. 1998, 38, 539-547. [CrossRef]

20. Rahman, M.; Beg, S.; Ahmad, M.Z.; Kazmi, I.; Akhter, S.; Ahmed, A. Omega-3 fatty acids as pharmacotherapeutics in psoriasis: Current status and future of nanomedicine in its effective delivery. Curr. Drug Targets 2013, 14, 708-722. [CrossRef] [PubMed]

21. Thangapazham, R.L.; Sharma, A.; Maheshwari, R.K. Beneficial role of curcumin in skin diseases. Adv. Exp. Med. Biol. 2007, 595, 343-357. [PubMed]

22. Kurd, S.K.; Smith, N.; VanVoorhees, A.; Troxel, A.B.; Badmaev, V.; Seykora, J.T.; Gelfand, J.M. Oral curcumin in the treatment of moderate to severe psoriasis vulgaris: A prospective clinical trial. J. Am. Acad. Dermatol. 2008, 58, 625-631. [CrossRef] [PubMed] 
23. Zenz, R.; Eferl, R.; Kenner, L.; Florin, L.; Hummerich, L.; Mehic, D.; Scheuch, H.; Angel, P.; Tschachler, E.; Wagner, E.F. Psoriasis-like skin disease and arthritis caused by inducible epidermal deletion of Jun proteins. Nature 2005, 437, 369-375. [CrossRef] [PubMed]

24. Florin, L.; Knebel, J.; Zigrino, P.; Vonderstrass, B.; Mauch, C.; Schorpp-Kistner, M.; Szabowski, A.; Angel, P. Delayed wound healing and epidermal hyperproliferation in mice lacking JunB in the skin. J. Investig. Dermatol. 2006, 126, 902-911. [CrossRef] [PubMed]

25. Kaneko, I.; Saini, R.K.; Griffin, K.P.; Whitfield, G.K.; Haussler, M.R.; Jurutka, P.W. FGF23 gene regulation by 1,25-dihydroxyvitamin D: Opposing effects in adipocytes and osteocytes. J. Endocrinol. 2015, 226, 155-166. [CrossRef] [PubMed]

26. Kuenzli, S.; Saurat, J.H. Peroxisome proliferator-activated receptors in cutaneous biology. Br. J. Dermatol. 2003, 149, 229-236. [CrossRef] [PubMed]

27. Niehues, H.; van Vlijmen-Willems, I.M.; Bergboer, J.G.; Kersten, F.F.; Narita, M.; Hendriks, W.J.; van den Bogaard, E.H.; Zeeuwen, P.L.; Schalkwijk, J. Late cornified envelope (LCE) proteins: Distinct expression patterns of LCE2 and LCE3 members suggest nonredundant roles in human epidermis and other epithelia. Br. J. Dermatol. 2016, 174, 795-802. [CrossRef] [PubMed]

28. Syed, D.N.; Lall, R.K.; Chamcheu, J.C.; Haidar, O.H.M. Involvement of ER stress and activation of apoptotic pathways in fisetin induced cytotoxicity in human melanoma. Arch. Biochem. Biophys. 2014, 563, 108-117. [CrossRef] [PubMed]

29. Huang, W.; Hennrick, K.; Drew, S. A colorful future of quantitative pathology: Validation of Vectra technology using chromogenic multiplexed immunohistochemistry and prostate tissue microarrays. Hum. Pathol. 2013, 44, 29-38. [CrossRef] [PubMed]

30. Chamcheu, J.C.; Adhami, V.M.; Esnault, S.; Sechi, M.; Siddiqui, I.A.; Satyshur, K.A.; Syed, D.N.; Dodwad, S.M.; Chaves-Rodriquez, M.I.; Longley, B.J.; et al. Dual inhibition of PI3K/AKT and mTOR by the dietary antioxidant, delphinidin, ameliorates psoriatic features in vitro and in an imiquimod-induced psoriasis-like disease in mice. Antioxid. Redox Signal 2017, 26, 49-69. [CrossRef] [PubMed]

31. De Cid, R.; Riveira-Munoz, E.; Zeeuwen, P.L.; Robarge, J.; Liao, W.; Dannhauser, E.N.; Giardina, E.; Stuart, P.E.; Nair, R.; Helms, C.; et al. Deletion of the late cornified envelope LCE3B and LCE3C genes as a susceptibility factor for psoriasis. Nat. Genet. 2009, 41, 211-215. [CrossRef] [PubMed]

32. Jurutka, P.W.; Remus, L.S.; Whitfield, G.K.; Thompson, P.D.; Hsieh, J.C.; Zitzer, H.; Tavakkoli, P.; Galligan, M.A.; Dang, H.T.; Haussler, C.A.; et al. The polymorphic N terminus in human vitamin D receptor isoforms influences transcriptional activity by modulating interaction with transcription factor IIB. Mol. Endocrinol. 2000, 14, 401-420. [CrossRef] [PubMed]

33. Speir, M.L.; Zweig, A.S.; Rosenbloom, K.R.; Raney, B.J.; Paten, B.; Nejad, P.; Lee, B.T.; Learned, K.; Karolchik, D.; Hinrichs, A.S.; et al. The UCSC genome browser database: 2016 update. Nucleic Acids Res. 2016, 44, D717-D725. [CrossRef] [PubMed]

34. Untergasser, A.; Nijveen, H.; Rao, X.; Bisseling, T.; Geurts, R.; Leunissen, J.A. Primer3plus, an enhanced web interface to primer3. Nucleic Acids Res. 2007, 35, W71-W74. [CrossRef] [PubMed]

35. Misund, K.; Selvik, L.K.; Rao, S.; Norsett, K.; Bakke, I.; Sandvik, A.K.; Laegreid, A.; Bruland, T.; Prestvik, W.S.; Thommesen, $\mathrm{L}$. Nr4a2 is regulated by gastrin and influences cellular responses of gastric adenocarcinoma cells. PLOS ONE 2013, 8, e76234. [CrossRef] [PubMed]

36. Johansen, C.; Kragballe, K.; Westergaard, M.; Henningsen, J.; Kristiansen, K.; Iversen, L. The mitogen-activated protein kinases P38 and ERK1/2 are increased in lesional psoriatic skin. Br. J. Dermatol. 2005, 152, 37-42. [CrossRef] [PubMed]

37. Ettehadi, P.; Greaves, M.W.; Wallach, D.; Aderka, D.; Camp, R.D. Elevated tumour necrosis factor-alpha (TNF- $\alpha$ ) biological activity in psoriatic skin lesions. Clin. Exp. Immunol. 1994, 96, 146-151. [CrossRef] [PubMed]

38. Bartik, L.; Whitfield, G.K.; Kaczmarska, M.; Lowmiller, C.L.; Moffet, E.W.; Furmick, J.K.; Hernandez, Z.; Haussler, C.A.; Haussler, M.R.; Jurutka, P.W. Curcumin: A novel nutritionally derived ligand of the vitamin D receptor with implications for colon cancer chemoprevention. J. Nutr. Biochem. 2010, 21, 1153-1161. [CrossRef] [PubMed] 
39. Chamcheu, J.C.; Chaves-Rodriquez, M.I.; Adhami, V.M.; Siddiqui, I.A.; Wood, G.S.; Longley, B.J.; Mukhtar, H. Upregulation of PI3K/AKT/MTOR, FABP5 and PPARBETA/DELTA in human psoriasis and imiquimod-induced murine psoriasiform dermatitis model. Acta Derm. Venereol. 2016, 96, 854-856. [PubMed]

40. Ham, S.A.; Hwang, J.S.; Yoo, T.; Lee, H.; Kang, E.S.; Park, C.; Oh, J.W.; Lee, H.T.; Min, G.; Kim, J.H.; et al. Ligand-activated PPAR $\delta$ inhibits UVB-induced senescence of human keratinocytes via PTEN-mediated inhibition of superoxide production. Biochem. J. 2012, 444, 27-38. [CrossRef] [PubMed]

41. Van de Kerkhof, P.C. An update on topical therapies for mild-moderate psoriasis. Derm. Clin. 2015, 33, 73-77. [CrossRef] [PubMed]

42. Barrea, L.; Macchia, P.E.; Tarantino, G.; Di Somma, C.; Pane, E.; Balato, N.; Napolitano, M.; Colao, A.; Savastano, S. Nutrition: A key environmental dietary factor in clinical severity and cardio-metabolic risk in psoriatic male patients evaluated by 7-day food-frequency questionnaire. J. Transl. Med. 2015, 13, 303. [CrossRef] [PubMed]

43. Guida, B.; Napoleone, A.; Trio, R.; Nastasi, A.; Balato, N.; Laccetti, R.; Cataldi, M. Energy-restricted, n-3 polyunsaturated fatty acids-rich diet improves the clinical response to immuno-modulating drugs in obese patients with plaque-type psoriasis: A randomized control clinical trial. Clin. Nutr. 2014, 33, $399-405$. [CrossRef] [PubMed]

44. Barrea, L.; Balato, N.; Di Somma, C.; Macchia, P.E.; Napolitano, M.; Savanelli, M.C.; Esposito, K.; Colao, A.; Savastano, S. Nutrition and psoriasis: Is there any association between the severity of the disease and adherence to the Mediterranean diet? J. Transl. Med. 2015, 13, 18. [CrossRef] [PubMed]

45. Lin, Y.L.; Pavlidis, P.; Karakoc, E.; Ajay, J.; Gokcumen, O. The evolution and functional impact of human deletion variants shared with archaic hominin genomes. Mol. Biol. Evol. 2015, 32, 1008-1019. [CrossRef] [PubMed]

46. Pajic, P.; Lin, Y.L.; Xu, D.; Gokcumen, O. The psoriasis-associated deletion of late cornified envelope genes $\angle C E 3 B$ and $L C E 3 C$ has been maintained under balancing selection since human denisovan divergence. BMC Evol. Biol. 2016, 16, 265. [CrossRef] [PubMed]

47. Bassaganyas, L.; Riveira-Munoz, E.; Garcia-Aragones, M.; Gonzalez, J.R.; Caceres, M.; Armengol, L.; Estivill, X. Worldwide population distribution of the common LCE3C-LCE3B deletion associated with psoriasis and other autoimmune disorders. BMC Genom. 2013, 14, 261. [CrossRef] [PubMed]

48. Bergboer, J.G.; Zeeuwen, P.L.; Schalkwijk, J. Genetics of psoriasis: Evidence for epistatic interaction between skin barrier abnormalities and immune deviation. J. Investig. Dermatol. 2012, 132, 2320-2331. [CrossRef] [PubMed]

49. Nakanishi, A.; Tsukamoto, I. n-3 polyunsaturated fatty acids stimulate osteoclastogenesis through PPAR $\gamma$-mediated enhancement of c-Fos expression, and suppress osteoclastogenesis through PPAR $\gamma$-dependent inhibition of NFKB activation. J. Nutr. Biochem. 2015, 26, 1317-1327. [CrossRef] [PubMed]

50. Victor, F.C.; Gottlieb, A.B. TNF-alpha and apoptosis: Implications for the pathogenesis and treatment of psoriasis. J. Drugs Dermatol. 2002, 1, 264-275. [PubMed]

51. Menter, A.; Gordon, K.B.; Leonardi, C.L.; Gu, Y.; Goldblum, O.M. Efficacy and safety of adalimumab across subgroups of patients with moderate to severe psoriasis. J. Am. Acad. Dermatol. 2010, 63, 448-456. [CrossRef] [PubMed]

52. Arthur, J.S.; Darragh, J. Signaling downstream of p38 in psoriasis. J. Investig. Dermatol. 2006, 126, $1689-1691$. [CrossRef] [PubMed]

53. Varma, S.R.; Sivaprakasam, T.O.; Mishra, A.; Prabhu, S.M.R.P.R. Imiquimod-induced psoriasis-like inflammation in differentiated human keratinocytes: Its evaluation using curcumin. Eur. J. Pharmacol. 2017, 813, 33-41. [CrossRef] [PubMed]

54. Yamagata, K.; Suzuki, S.; Tagami, M. Docosahexaenoic acid prevented tumor necrosis factor alpha-induced endothelial dysfunction and senescence. Prostaglandin. Leukot Essent Fatty Acids 2016, 104, 11-18. [CrossRef] [PubMed]

55. Bernardo, A.; Giammarco, M.L.; De Nuccio, C.; Ajmone-Cat, M.A.; Visentin, S.; De Simone, R.; Minghetti, L. Docosahexaenoic acid promotes oligodendrocyte differentiation via PPAR- $\gamma$ signalling and prevents tumor necrosis factor-alpha-dependent maturational arrest. Biochim. Biophys. Acta 2017, 1862, 1013-1023. [CrossRef] [PubMed] 
56. Kim, B.E.; Howell, M.D.; Guttman-Yassky, E.; Gilleaudeau, P.M.; Cardinale, I.R.; Boguniewicz, M.; Krueger, J.G.; Leung, D.Y. TNF- $\alpha$ downregulates filaggrin and loricrin through c-Jun N-terminal kinase: Role for TNF- $\alpha$ antagonists to improve skin barrier. J. Investig. Dermatol. 2011, 131, 1272-1279. [CrossRef] [PubMed]

57. O’Kane, M.; Markham, T.; McEvoy, A.N.; Fearon, U.; Veale, D.J.; FitzGerald, O.; Kirby, B.; Murphy, E.P. Increased expression of the orphan nuclear receptor NURR1 in psoriasis and modulation following TNF- $\alpha$ inhibition. J. Investig. Dermatol. 2008, 128, 300-310. [CrossRef] [PubMed]

58. Raveney, B.J.; Oki, S.; Yamamura, T. Nuclear receptor NR4A2 orchestrates Th17 cell-mediated autoimmune inflammation via IL-21 signalling. PLoS ONE 2013, 8, e56595. [CrossRef] [PubMed]

59. Deng, Y.; Chang, C.; Lu, Q. The inflammatory response in psoriasis: A comprehensive review. Clin. Rev. Allergy Immunol. 2016, 50, 377-389. [CrossRef] [PubMed]

60. Moriwaki, Y.; Takada, K.; Tsuji, S.; Kawashima, K.; Misawa, H. Transcriptional regulation of SLURP2, a psoriasis-associated gene, is under control of IL-22 in the skin: A special reference to the nested gene LYNX1. Int. Immunopharmacol. 2015, 29, 71-75. [CrossRef] [PubMed]

61. Lu, Y.; Tian, H.; Hong, S. Novel 14,21-dihydroxy-docosahexaenoic acids: Structures, formation pathways, and enhancement of wound healing. J. Lipid Res. 2010, 51, 923-932. [CrossRef] [PubMed]

(c) 2018 by the authors. Licensee MDPI, Basel, Switzerland. This article is an open access article distributed under the terms and conditions of the Creative Commons Attribution (CC BY) license (http://creativecommons.org/licenses/by/4.0/). 